\title{
WestVirginiaUniversity
}

THE RESEARCH REPOSITORY @ WVU

Graduate Theses, Dissertations, and Problem Reports

2018

\section{An experimental investigation of the banana dehydration process.}

Donnique Kim Denise Sherman

Follow this and additional works at: https://researchrepository.wvu.edu/etd

\section{Recommended Citation}

Sherman, Donnique Kim Denise, "An experimental investigation of the banana dehydration process." (2018). Graduate Theses, Dissertations, and Problem Reports. 3972.

https://researchrepository.wvu.edu/etd/3972

This Problem/Project Report is protected by copyright and/or related rights. It has been brought to you by the The Research Repository @WVU with permission from the rights-holder(s). You are free to use this Problem/Project Report in any way that is permitted by the copyright and related rights legislation that applies to your use. For other uses you must obtain permission from the rights-holder(s) directly, unless additional rights are indicated by a Creative Commons license in the record and/ or on the work itself. This Problem/Project Report has been accepted for inclusion in WVU Graduate Theses, Dissertations, and Problem Reports collection by an authorized administrator of The Research Repository @ WVU. For more information, please contact researchrepository@mail.wvu.edu. 


\title{
An Experimental Investigation of the Banana Dehydration Process
}

\author{
Donnique Sherman
}

Problem Report Submitted to the Benjamin M. Statler College of Engineering and Mineral Resources at West Virginia University in partial fulfillment of the requirements for the degree of

\author{
Master of Science \\ In \\ Energy Systems Engineering
}

\author{
Hailin Li, Ph.D., Chair \\ Roger Chen, Ph.D.
}

Bhaskaran Gopalakrishnan, Ph.D.

\author{
Morgantown, West Virginia \\ 2018
}

Keywords: Banana, Dehydration, Convective Drying, Power, Humidity 


\section{ABSTRACT \\ An Experimental Investigation of the Banana Dehydration Process \\ Donnique Sherman}

Drying food is one of the well-known methods of food preservation. Food preservation methods, like drying, slow down the deterioration of foods as well as prevents the growth of microorganisms. Food preservation allows for an extension of shelf life and prevents food from spoiling. The method used in this study is known as convective or direct drying. As the ambient air heats up from a convective source the relative humidity reduces which accelerates the drying force and decreases drying time. The reduction in relative humidity allows for moisture to move from the food, such as banana chips, to the air. As the hot air flows over the solid, the moisture content of the solid begins to decrease, and the solid begins to heat up. Then, the heated solid starts to release water from the interior of the solid to the surface and eventually dissipates into the air.

In this project, a Presto ${ }^{\circledR}$ Dehydro ${ }^{\mathrm{TM}}$ food dehydrator was used to dehydrate chips of bananas to test different parameters such as the environmental settings, the shape, and size of the bananas, preparation, air flow, and temperature in order to explore its impacts on drying time and moisture loss. There were two sets of tests done. The first set of tests examined the effects of the size of the banana chips, temperature, and pretreatment on drying time and moisture loss. The second set of tests investigated the environmental effects, and air velocity on moisture loss. The impacts of these parameters are then analyzed in this study. Concluding that the shape and size of the banana did affect the drying time. The thicker the banana chips were the longer it took for the chips to dehydrate. The thinner the cut, the less moisture the slice contains, and the less moisture the dehydrator had to remove. The faster the fan air velocity was the better the hot air was distributed throughout the dehydrator system and the more water was expelled from the bananas. The test data displayed, that the high fan speed tests removed moisture at a faster rate than at medium and low fan speeds. A baseline was then established for the relationship between the fan speed and the drying time and equations were created to display it. Through the different environmental settings tested, it was shown that the lower relative humidity allows for more moisture weight to be lost. Therefore, to speed up the drying time there needs to not only be high temperatures but low relative humidity as well to increase the rate of moisture removal. 


\section{Acknowledgment}

I would like to acknowledge every one of the professors on my committee: my graduate advisor Dr. Hailin Li for his support and understanding throughout this process. Your willingness to contribute constructive input into my work molded me into a better student. As well as, Dr. Roger Chen and Dr. Bhaskaran Gopalakrishnan for their strong support and patience. Without you all, achieving this degree would not have happened.

I would like to thank God, my family, and friends for their everlasting support throughout my academic career. Your support has carried me through many challenges that lead me to many successes.

I appreciate and want to thank everyone who has helped me along the way. Your support and guidance will never be forgotten, and for this, I am forever grateful. 


\section{Table of Contents}

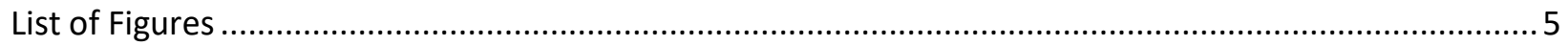

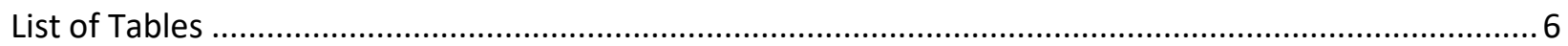

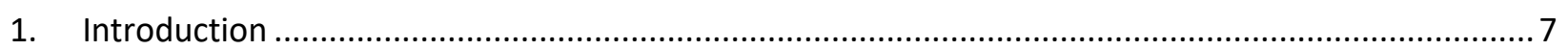

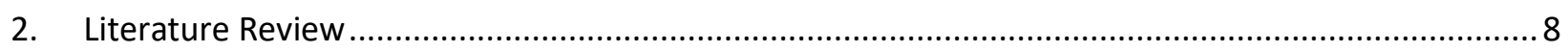

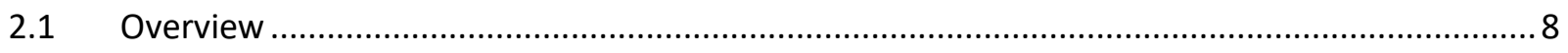

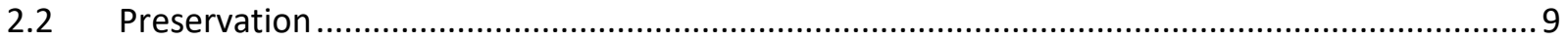

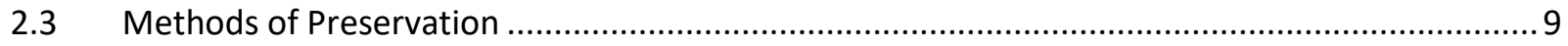

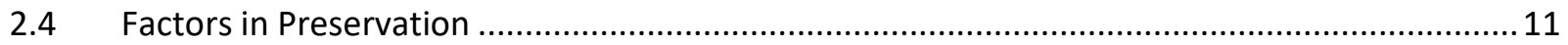

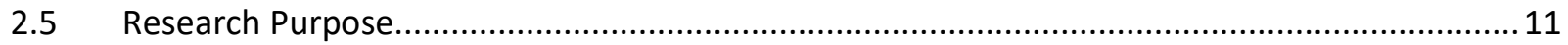

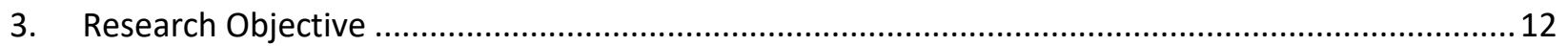

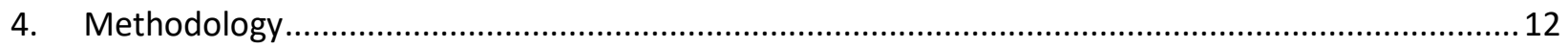

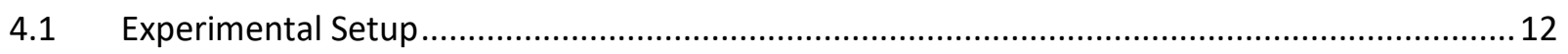

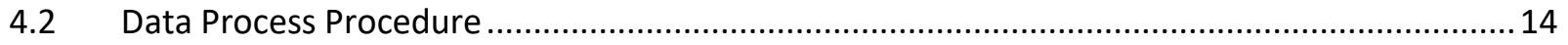

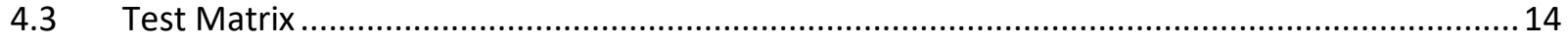

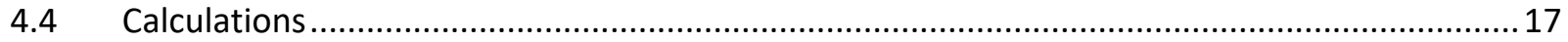

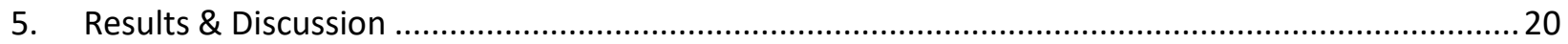

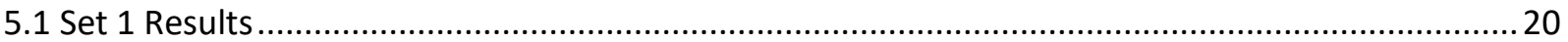

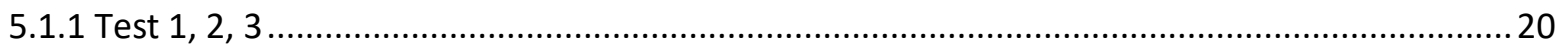

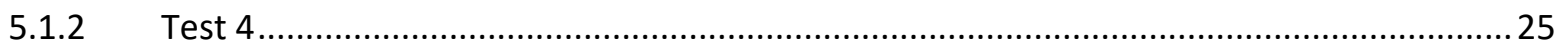

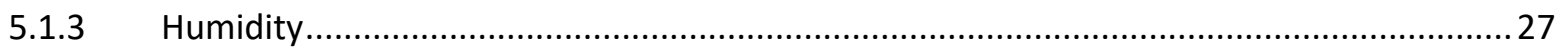

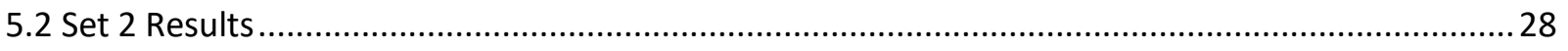

5.2.1 Impact of Air Velocity on Moisture Weight Lost.............................................................28

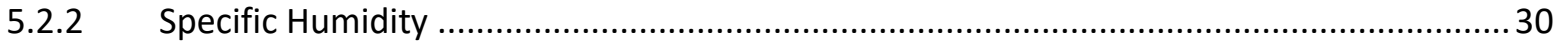

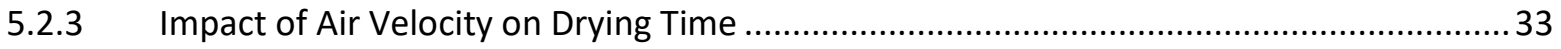

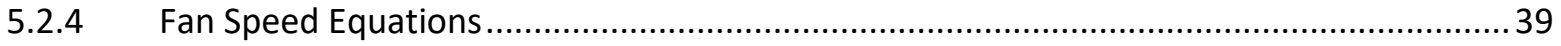

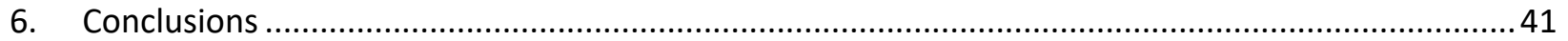

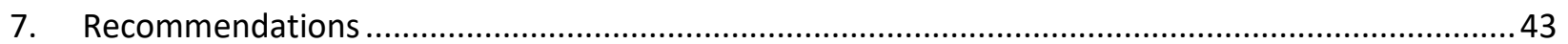

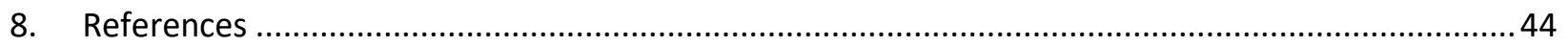

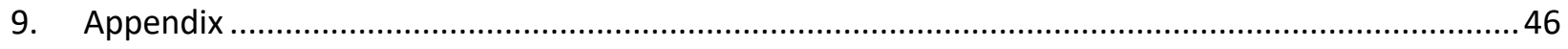

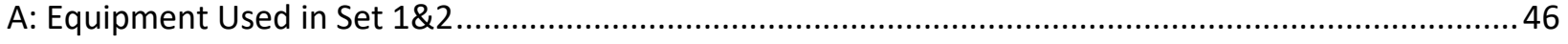

B: Set 2 Equipment Setup \& Other Photos ……............................................................................... 50

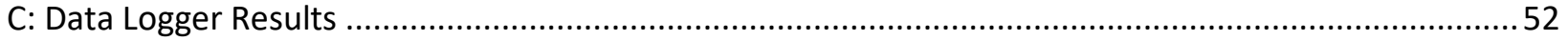




\section{List of Figures}

Figure 1: Presto $^{\circledR}$ Dehydro $^{\mathrm{TM}}$ electric Food Dehydrator (Yermudder, 2017)............................................. 8

Figure 2: Pictures of the different size and shaped chips. Left to Right(both pictures): diagonal thin, circle

thick, diagonal thick, circle thin ..14

Figure 3: Variation of temperature through time at the outlet and inlet of the dehydrator measured in

Test 1

Figure 4: Variation of temperature through time at the outlet and inlet of the dehydrator measured in

Test 2

Figure 5: Variation of temperature through time at the outlet and inlet of the dehydrator measured in

Test 3

Figure 6: Effect of time on the moisture content of different sized banana chips measured in Test 1 .....23

Figure 7: Effect of time on the moisture content of different sized banana chips measured in Test 2 ..... 23

Figure 8: Effect of time on the moisture content of different sized banana chips measured in Test 3 .....24

Figure 9: Variation of temperature through time and the Top, Middle, and Bottom Racks measured in

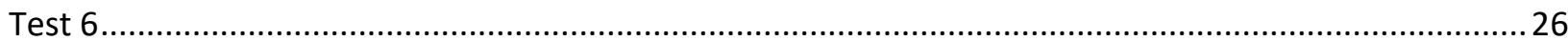

Figure 10: Effect of moisture removed (grams) on time of Top, Middle, and Bottom Racks Test 4 ..........26

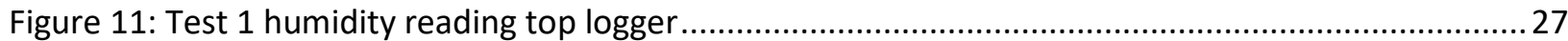

Figure 12: Variation of moisture content in relation to operating time in Case 1 ................................33

Figure 13: Variation of moisture content in relation to operating time in Case 2 ...................................34

Figure 14: Variation of moisture content in relation to operating time in Case 3 .................................35

Figure 15: Variation of moisture content in relation to operating time in Case 4 ..................................36

Figure 16: Low fan speed impact of moisture loss in relation to time graph Case 1-4 ............................37

Figure 17: Medium fan speed impact of moisture loss in relation to time graph Case 1-4 ......................38

Figure 18: High fan speed impact of moisture loss in relation to time graph Case 1-4..........................39

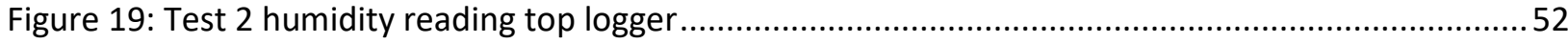

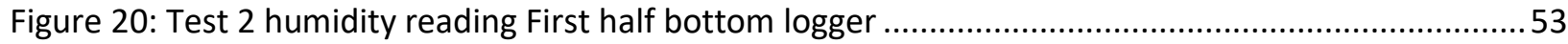

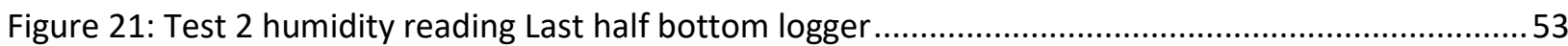

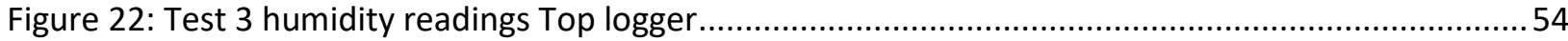

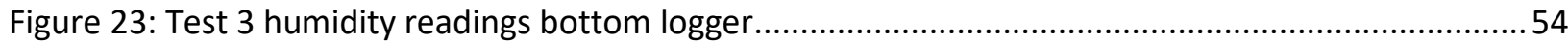

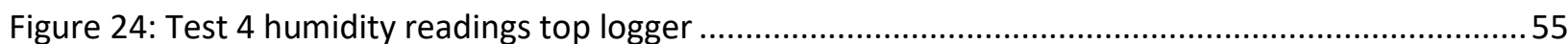

Figure 25: Test 4 humidity readings bottom logger...........................................................................5 


\section{List of Tables}

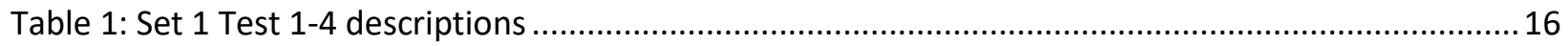

Table 2: Measured Speeds of the heating fan at the high, medium, and low settings ...........................17

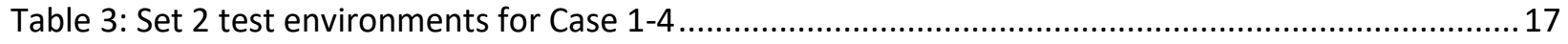

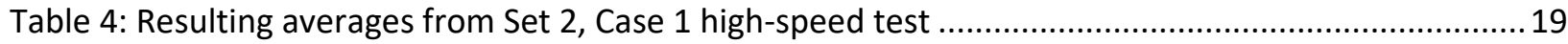

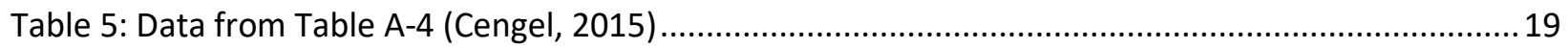

Table 6: Average Temperature and Moisture Removal Rate for each rack position in Test 4 ..................27

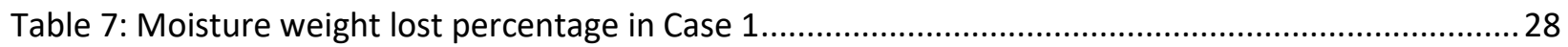

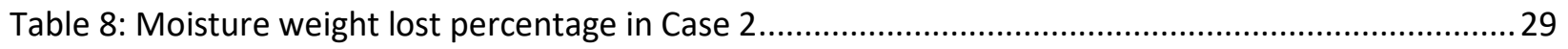

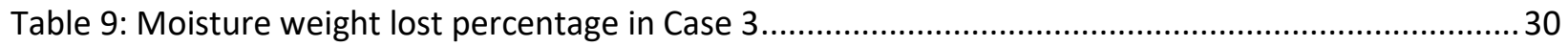

Table 10: Moisture weight lost percentage in Case 4....................................................................... 30

Table 11: Avg. Relative Humidity, Avg. Temperature, and Specific Humidity of Case 1 and Case 2 from the top and bottom sensors of the dehydrator system ...........................................................................32

Table 12: Avg. Relative Humidity, Avg. Temperature, and Specific Humidity of Case 3 and Case 4 based on average data from the top and bottom sensors of the dehydrator system .......................................32

Table 13: Low-speed Case 1-4 segmented regression slopes and average ...............................................38

Table 14: Medium speed Case 1-4 segmented regression slopes and average ........................................38

Table 15: Low-speed Case 1-4 segmented regression slopes and average ............................................39

Table 16: Moisture loss rates of the high, medium, and low speed tests of Case 1,2,3, and $4 \ldots \ldots \ldots \ldots \ldots . . . .40$

Table 17: Low fan speed segmented regression equations............................................................... 41

Table 18: Medium and high speed segmented regression equations.....................................................41 


\section{Introduction}

Drying food is one of the oldest methods of food preservation, evidence of use has dated back to 12,000

B.C. (Nummer, 2002). Methods of food preservation, like drying, slow down the deterioration of foods as well as prevents the growth of microorganisms. Food preservation allows for an extension of shelf life and prevents food from spoiling.

One of the oldest techniques of drying food is by using the sun, known as Solar drying. This method uses the sun to dry the products in the natural environment. This technique is hard to control, and it has to be done in a high heat low humidity space to avoid microbial growth. Typically, the product is hung outside to dry, and after a 3 to 4 day period, the product is dry and ready to be used (Troftgruben, 1984).

The method used in this study is known as convective or direct drying. As the ambient air heats up from a convective source the relative humidity reduces which accelerates the drying force and drying time. The reduction in humidity allows for moisture to dissipate from the solid to the air. As the hot air flows over the solid, the moisture content of the solid begins to decrease, and the solid begins to heat up. The heated up solid starts to then move water from the interior of the solid to the surface to be moved into the air. In this project, a Presto ${ }^{\circledR}$ Dehydro $^{\mathrm{TM}}$ food dehydrator was used to dehydrate chips of bananas in order to test different parameters of the intake ambient air, the size of the banana chips, pretreatment, and their impacts of moisture lost through time.

In this research, two sets of tests were conducted. The first set evaluated the influence of temperature, pretreatment, and the size of the banana chips on the dehydration process. The next set of tests was conducted to evaluate the influence of air speed and intake air properties on the dehydration process of the banana chips. 


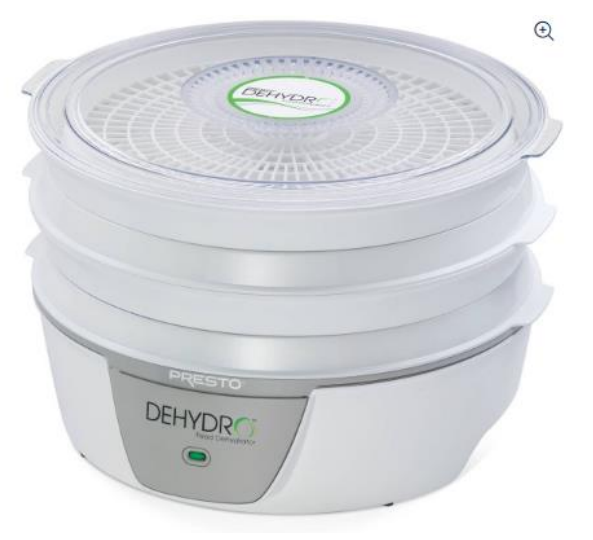

Figure 1: Presto ${ }^{\circledR}$ Dehydro ${ }^{\text {TM }}$ electric Food Dehydrator (Yermudder,2017)

\section{Literature Review}

\subsection{Overview}

Throughout history, humans have evolved to survive the different elements on Earth. Physically we evolved to deal with certain climates, like our noses for instance. Archeologists have theorized that the variations of the shape of the human nasal cavity may have relevance to the environments of their ancestors. The nasal cavity plays an important role in warming or cooling the air before it reaches the lungs (Noback et al, 2011). The narrower the nose the higher the contact is between the air and mucosal tissue, which helps to warm the air before it reaches the lungs. The wider the nose, the less it enhances contact, cooling down the air before it reaches the lungs. Theorizing that the nasal cavity size evolved to suit the environment their ancestors lived in. Further theorizing that those with larger noses have ancestral connections to those living in hotter environments and those with smaller noses may have ancestral connections to those living in colder climates (Noback et.al, 2011). Even though this is still a topic of research, there is an understanding that the human has evolved to survive based on its surroundings. Outside of physical evolutions, another key to human survival is food, and the process of preserving it has been evolving throughout history (Raymond, 2011). The process of preserving food allows for the length of time in which food is nutritionally valuable to be extended. Being able to understand food preservation is essential to the world's food supply. 


\subsection{Preservation}

In times when food is not in season or food is not plentiful, preserving food can become very useful. Preserving food has been a vital part in reducing the amount of food wasted due to natural spoiling times. Even with the different methods of preservation used in ancient times, the science behind why those methods slowed the deterioration of foods wasn't fully understood until 1864. In 1864 Louis Pasteur demonstrated through pasteurization, that by slowing down microbial growth, the amount of time it takes for food to spoil would be extended. Furthermore, making the connection that by reducing microorganisms or their growth in foods can reduce spoiling times (History of Food, 2011). Since then, preserving food has become far more advanced and the understanding of food illnesses has increased as well.

\subsection{Methods of Preservation}

\subsubsection{Drying}

Drying is a process of removing water from food so that it stops the growth of microorganisms and bacteria to keep the product from spoiling. One early preservation method includes using the Sun and wind to dry foods naturally. Drying foods as early as 12,000 B.C. were evidenced in the Middle East and in Oriental cultures (Nummer, 2012). The dried foods also gave evidence to the main food supplies of fish, and wild game. As different types of foods became available, the practice of drying evolved. In the middle ages, fire was used to create heat and dry foods. Still, houses were created, as well, to dry herbs, and other foods (Linda, 2017a).

\subsubsection{Drying: Dehydration}

In 1795, the first-ever dehydrator was introduced in France (History of Food, 2011). Dehydrating food was very important for times when the food supply was short, like during the winter. Dehydrated food became more commercialized during the Civil War (Linda, 2017a). The process of dehydration continued to evolve. The modern dehydrator can dry food in a matter of hours, has advanced specifications that allow the drying environment to be controlled and ideal for dehydrating any type of food. There are 
many current dehydration techniques: smoking, solar, convective, drum, spray, fluidized-bed, and freezing (Cohen, 1995).

\subsubsection{Freezing}

Freezing became used as a method of food preservation originally because of the climate in certain geographic areas. The temperatures would get below freezing and meat and other foods would be set outside to be preserved (Linda, 2017a). Freezing preserves food by using its low temperature to make pathogens inactive. The low temperatures slow down the movement of the microorganisms, in turn having them become dormant. In the early 1900s, Clarence Birdseye developed the quick freeze process (Nummer, 2002). His invention started the basis of what the modern frozen food industry is today.

\subsubsection{Fermentation}

Fermentation was evidenced to be used around 10,000 B.C. to make bread and to produce alcoholic beverages (Linda, 2017a). The fermentation process is converting carbohydrates to alcohol or organic acids using microorganisms under anaerobic conditions. The microorganism's growth reduces the $\mathrm{pH}$ of the food to a range where pathogenic and many spoilage organisms won't grow-allowing foods shelf life to be extended.

\subsubsection{Pickling}

Pickling is the process of immersion in vinegar or through fermentation in brine. Pickling uses an acidic liquid to raise the $\mathrm{pH}$ of the food to a range where pathogens cannot grow. Therefore, allowing the shelf life of the pickled food to be extended. According to the New York Food Museum, archeologists believe that the ancient Mesopotamians pickled food as far back as 2400 B.C. (Terenelsk \& Ralph, 2003).

\subsubsection{Curing}

The process of curing uses salt, sugar, or nitrates to draw out the moisture in food. Other curing processes involves spicing and smoking. The process of curing was evidenced to be used as early as 3000 B.C. in Mesopotamia (History of Meat, 2014). Curing draws out moisture in an effort to reduce microbial growth and in turn, slows down the process of spoiling. 


\subsubsection{Canning}

Canning is the process in which foods are placed in cans or jars and heated up to kill any

microorganisms. The heating, and then cooling effect, creates a vacuum seal that prevents other microorganisms from contaminating the food in the jar or can. Canning was discovered by Nicolas Appert in the 1800s (Nummer, 2002). He discovered that the process was used for wine, and then he applied it to food and found that it preserved the food from deterioration.

\subsection{Factors in Preservation}

Through the different methods of preservation, it can be understood that temperature, water activity, and $\mathrm{pH}$ are all factors that affect preservation (Gould, 1995). At $0^{\circ} \mathrm{F}$, microbes become inactive in foods and eliminate microbial growth (USDA, 2013). Hotter temperatures, help in boiling and sterilizing cans and jars, as well as the use of fire and smoke to dry out the foods to reduce microbial growth. Water activity and moisture influence the stability and safety of food. Moisture in food is an aiding agent in microbial growth. Being able to reduce the water activity in food, allows for a reduction in spoiling and growth of microorganisms. The factor of $\mathrm{pH}$ was also used to create an environment too acidic for any microorganism to grow.

\subsection{Research Purpose}

All in all, there are several ways to preserve foods. The methods of preservation are effective because they control microbial growth and slow spoiling time by controlling the $\mathrm{pH}$, the temperature, and by reducing the moisture activity. Dehydration, as a method of preservation, has been well researched but discovering what factors can make the process of dehydration more effective and efficient could further the knowledge of drying mechanics. In this study, different factors of food shape, environmental settings, temperature, and preparation are tested using modern dehydration methods to see how they affect drying time and moisture loss of the food through time. 


\section{Research Objective}

The objective of this research was to dehydrate bananas in the Presto ${ }^{\circledR}$ Dehydro ${ }^{\mathrm{TM}}$ Electric Food

Dehydrator, in order to determine the impact of different factors like preparation, size, and shape of the bananas, temperature, humidity, and environmental settings. This helps to further understand drying mechanics and expand on the knowledge of preservation methods.

\section{Methodology}

\subsection{Experimental Setup}

\subsubsection{Overview}

In order to explore these objectives, there were two sets of tests done. The first set of tests were used to investigate the impact on the size and shape of the banana chips, temperature, and pretreatment on moisture lost through time. The second set of tests were done to see how different environments, and different air velocities moisture lost through time. At the start of each test, and every hour during the test, the weight and moisture content of the bananas were measured. The mass of the bananas was measured using a precision scale and the moisture content of the bananas was measured using an EXTECH Moisture Psychrometer. The air flow speed in Set 2 was measured using the EXTECH Anemometer. The temperature and humidity were measured every thirty seconds of the tests using two EXTECH Temperature and Humidity sensors. The power consumption of the tests in Set 1 was recorded using the OM-DVCV. All of the equipment used for the test are discussed below.

\subsubsection{Equipment}

Dehydrator: The dehydrator used was the Presto ${ }^{\circledR}$ Dehydro ${ }^{\mathrm{TM}}$ Electric Food Dehydrator model 06300. The power consumption is 600 watts. The drying time is about 7-8 hours depending on the food. In this 
research, the dehydrator was modified so that the fan speed can be adjusted. A six-inch diameter PVC pipe was installed at the outlet for the convenience of measuring the air velocity and flow rate.

Air Velocity Measurement: The air velocity was measured using the EXTECH Thermo-Anemometer model AN100. The anemometer measures in knots, kilometers/hour, miles/hour, meters/second, and feet/min. This instrument was used to record the outlet and inlet air velocity of the dehydrator.

Scale: The scale used was the Ohaus AV812 Adventurer Pro Digital Balance 810 x $0.01 \mathrm{~g}$ with InCal. The scale was used to measure the mass of the banana chips at every hour during each test and the beginning and end of each test. The variation of the mass was used to calculate the mass of the moisture lost every hour.

Data Sampling and Recording: The data logger used was the EXTECH Temperature and Humidity Datalogger model 42275. Two data loggers were used in this research. The data loggers recorded temperature and the relative humidity of the air every thirty seconds.

Moisture Content: The moisture content was measured using the EXTECH Moisture Psychrometer + IR Thermometer model M0297. The probe attachment was inserted into the banana slice to measure the percentage of moisture it contained.

\subsubsection{Used in Set 1 Only}

Humidity: The EXTECH Big Digit Remote Probe Hygro-Thermometer model 445715 was used only in Test 1. In Test 1 it was used to record the humidity and temperature. Proven to not work after the temperature reached 140 degrees Fahrenheit and its use was discontinued.

Temperature: 2-Channel K-Type Microprocessor Digital Thermometer Thermocouple Sensor 2 Probes was used to measure the temperature of the different racks, as well as the inlet and outlet throughout the tests. 
Power consumption: The power consumed from Test 2-6 was measured and recorded by the Omega OM-DVCV datalogger. The data logger measured the amount of voltage consumed.

\subsubsection{Equipment used in Set 2 Only}

Steam Additive: The steamer used was the Shark Garment Stand Steamer model GS300. The steamer power consumption was 1200 Watts and the water capacity was $1150 \mathrm{ml}$. The hose of the steamer was attached to the inlet of the dehydrator to input steam in order to increase the relative humidity.

\subsection{Data Process Procedure}

For each test, every hour the mass of the banana chips, their temperature, and moisture content were measured and recorded in Excel. All of the sensor data was loaded into Excel after each test as well. The sensor data recorded the humidity and temperature every thirty seconds.

\subsection{Test Matrix}

\subsubsection{Set 1}

In Set 1, there was a total of six different tests performed. The first two tests were preliminary. The next two tests ran for nine hours and recorded power consumption, moisture content over time, and used different banana slice shapes (Figure 2) and sizes. During the last two tests, the bananas were pretreated and power consumption, moisture content over time, and different slice shapes and sizes were recorded. The last test was set up to investigate the effect that temperature had on the rate of moisture loss. The test recorded power consumption and moisture loss over time.

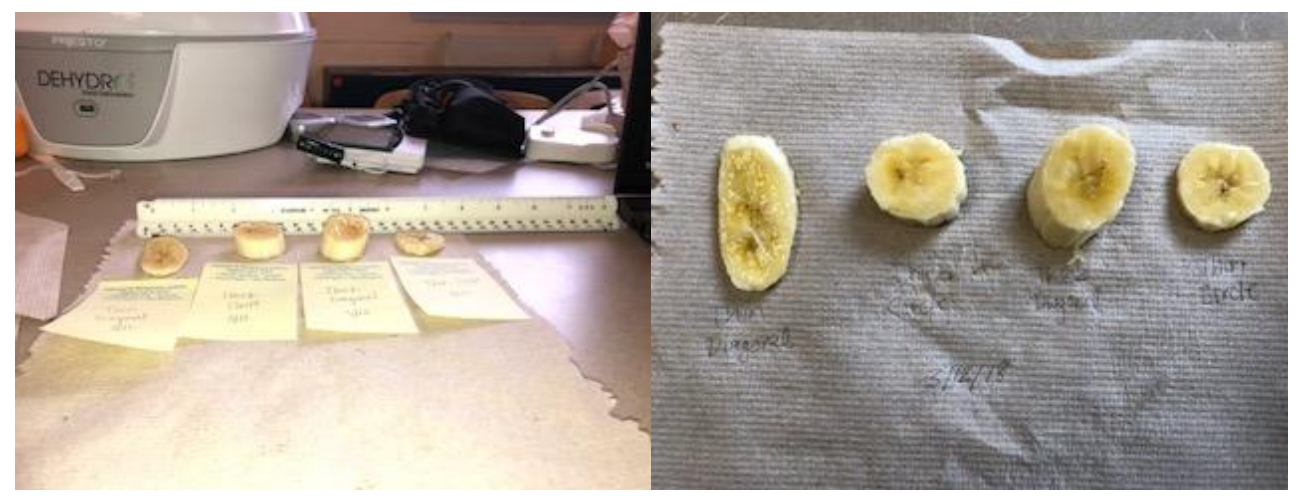

Figure 2: Pictures of the different size and shaped chips. Left to Right(both pictures): diagonal thin, circle thick, diagonal thick, circle thin 


\subsubsection{Test 1 \& 2}

Two bananas were sliced in thin circles, two bananas were sliced in thick circles, two bananas were sliced in thin diagonals, and two bananas were sliced in thick diagonals. The different shapes of the chips allow for a comparison to be made between them in relation to drying time and moisture loss through time. After the bananas are sliced up, all of the same sized/shaped chips were put on the same rack. Therefore, totaling four racks to be stacked for each differently shaped banana chips. The dehydrator was then turned on. The outlet and inlet temperature and moisture content of each different shape of the banana slice were recorded every hour. After each hour the top rack was rotated to the bottom to ensure even drying. The weight of the bananas was recorded at the beginning and end of the test.

\subsubsection{Test 3}

Two bananas were sliced in thin circles, two bananas were sliced in thick circles, two bananas were sliced in thin diagonals, and two bananas were sliced in thick diagonals. Then the bananas were pretreated, by soaking them in a mixture of equal parts lemon juice and water for ten minutes. The pretreatment helps with the color of the bananas. The different shapes of the chips allowed for a comparison to be made among them in relation to drying time and moisture loss through time. After the pretreatment, all of the same sized/shaped chips were put on the same rack. Therefore, totaling four racks to be stacked for each differently shaped banana chips. The dehydrator was then turned on, and at every hour the outlet and inlet temperature, the moisture content of each different shape of a banana slice, was recorded. After each hour the top rack was rotated to the bottom to ensure even drying. Mass of the bananas was measured at the beginning and end of each hour.

\subsubsection{Test 4}

The main objective of this test was to see how much moisture is being removed from the bananas at different temperatures, in order to determine how temperature affects drying time. To do this, six bananas were cut in circle thin chips, pretreated, and put into three different racks. Seven racks were stacked together and the bottom, middle, and top racks held bananas. There were two empty racks put in between the bottom and middle rack and the middle and top rack to create different temperature 
environments. The racks were separated by 4 inches to create a temperature variation. The bottom rack was closest to the heating element so the temperature at the bottom rack is the highest (hot), and the top rack is the farthest from the heating element, so it reached the lowest temperature of the three racks holding bananas (cold). The temperature, mass, and moisture content were recorded in each hour for each of the top, middle, and bottom racks.

Table 1: Set 1 Test 1-4 descriptions

\begin{tabular}{|c|c|c|c|c|}
\hline & Test 1 & Test 2 & Test 3 & Test 4 \\
\hline Test Type & Normal & Normal & Normal & $\begin{array}{l}\text { Temp. } \\
\text { Difference }\end{array}$ \\
\hline Chip Shape & $\begin{array}{l}\text { Circle Thin } \\
\text { Circle Thick } \\
\text { Diagonal } \\
\text { Thin } \\
\text { Diagonal } \\
\text { Thick }\end{array}$ & $\begin{array}{l}\text { Circle Thin } \\
\text { Circle Thick } \\
\text { Diagonal } \\
\text { Thin } \\
\text { Diagonal } \\
\text { Thick }\end{array}$ & $\begin{array}{l}\text { Circle Thin } \\
\text { Circle Thick } \\
\text { Diagonal } \\
\text { Thin } \\
\text { Diagonal } \\
\text { Thick }\end{array}$ & Circle Thin \\
\hline Pre-treated & No & No & Yes & Yes \\
\hline $\begin{array}{l}\text { Dehydration } \\
\text { Time (hour) }\end{array}$ & 9 & 9 & 10 & 9 \\
\hline
\end{tabular}

\subsubsection{Set 2}

In Set 2, three racks were used, the original heating fan was replaced by a three-spread fan, allowing the change in air velocity by altering the speed of the fan of each test. The middle rack out of the total three racks in the dehydration system was where the bananas were placed. The dehydration chamber was lined with parchment paper and weighed on a precision scale. Then two bananas were sliced in quarter inch chips and placed on the lined rack and weighted. A sensor was placed on the rack with the bananas and the second sensor was placed in the outlet chamber. The sensors capture the humidity and temperature of the air throughout the entire drying time. The moisture content of the bananas is measured. Then the dehydration system heating element is turned on as well as the fan. At every hour, the mass and moisture content of the banana was measured. Once the rack of banana chips has reached a measured moisture content of $<25 \%$, which was determined by the Center for Agribusiness and Rural Development to be considered dehydrated, the test is completed (Timmermans, 2012). This set of tests 
examined the impact of ambient air moisture on the dehydration process. Each test was repeated for three fan speed settings: high, medium, and low. The air velocity was measured using the ThermoAnemometer.

Table 2: Measured Speeds of the heating fan at the high, medium, and low settings

\begin{tabular}{|c|l|}
\hline Fan Speed Setting & Speed, $\mathbf{m} / \mathbf{s}$ \\
\hline High & 3.81 \\
\hline Medium & 2.65 \\
\hline Low & 1.65 \\
\hline
\end{tabular}

There were four different environmental cases tested. The air-conditioned environment case was tested in a room where the air conditioning was running. The no air conditioning environment case was tested in a room where the air was not being conditioned. The steam added environment case was tested in a room where air conditioning was running. The steam generated by the Shark Fabric Steamer was added into the intake air of the dehydrator so that the relative humidity of the dehydration environment was increased. The outside environment ran tests in the outside ambient air, where there was no control over the temperature and humidity.

Table 3: Set 2 test environments for Case 1-4

\begin{tabular}{|l|l|l|l|l|}
\hline Case & Case 1 & Case 2 & Case 3 & Case 4 \\
\hline Environment & $\begin{array}{l}\text { Tested inside a } \\
\text { room in a building } \\
\text { with no air } \\
\text { conditioning }\end{array}$ & $\begin{array}{l}\text { Tested inside a } \\
\text { room in a building } \\
\text { with air } \\
\text { conditioning }\end{array}$ & $\begin{array}{l}\text { Tested inside a } \\
\text { room in a building } \\
\text { with air } \\
\text { conditioning and } \\
\text { with added steam }\end{array}$ & $\begin{array}{l}\text { Tested outside of } \\
\text { a building with } \\
\text { natural conditions }\end{array}$ \\
& & & \\
\hline
\end{tabular}

\subsection{Calculations}

\subsubsection{Moisture Weight Lost}

In this study, the moisture weight lost was calculated to determine the percentage of moisture that was removed from the bananas until the point of dehydration. Using the initial moisture content measured, and the initial total mass of the bananas, the weight of the moisture in the bananas were determined at the beginning of the tests. Then after the test was completed, the dried bananas were weighed again, and the moisture content was recorded. If the moisture content is less than $24 \%$, the weight at $24 \%$ 
moisture content is determined through interpolation. The dehydrated moisture weight loss was calculated, and a percent loss equation is used to determine the amount of moisture that was removed. The equations used are below.

$$
\begin{aligned}
& \text { Moisture content weight }=\text { Moisture content }(\%) * \text { Mass }(\text { grams }) \\
& \text { If the final moisture content is }<24 \%, y_{2} \text { mass@24\% }=\frac{\left(x_{2}-x_{1}\right)\left(y_{3}-y_{1}\right)}{\left(x_{3}-x_{1}\right)}+y_{1} \\
& \text { Total Moisture Weight Lost, } \%=\frac{\text { Initial Moisture Weight }- \text { Final Moisture Weight }}{\text { Initial Moisture Weight }} * 100 \%
\end{aligned}
$$

\subsubsection{Moisture Lost Equation}

The moisture content each hour of operation in each test for all three speeds were graphed, and the rate of moisture removal was determined through each cases trendline slope. The rate of moisture removal was averaged for each case. The equation is set up in the slope-intercept form. Where $y$ is the moisture content of the bananas, $m$ is the slope or the rate of moisture content over time, $x$ is the number of hours, and $b$ is the moisture content of bananas at time zero. With knowing the moisture content of bananas at time zero, an equation can be generated based on air velocity of the estimated moisture content at any hour inputted.

\section{Calculating the equations}

$$
\text { High Speed: } \frac{-9.06+(-9.59)+(-9.46)+(9.57)}{4}=-9.42
$$

The average rate of moisture removal per hour is $9.42 \%$ at high fan speed. Given the moisture content of the fruit at time zero, for example, if it is $75 \%$, the equation would be $y=-9.42 x+75$.

\subsubsection{Specific Humidity}

In order to understand how much moisture was being carried by air, an Excel file was created to determine the specific humidity of the air inside and leaving the dehydrator system. By calculating the specific humidity of each case a comparison can be made to one another. The specific humidity is the 
ratio of $\mathrm{kg}$ of $\mathrm{H}_{2} \mathrm{O}$ to a $\mathrm{kg}$ of dry air. In order to determine this comparative measure, the temperature and relative humidity of each test were averaged.

Table 4: Resulting averages from Set 2, Case 1 high-speed test

\begin{tabular}{|l|l|}
\hline Avg. Temperature $\left({ }^{\circ} \mathrm{F}\right)$ & Avg. Relative Humidity (\%) \\
\hline 144 & 12.1 \\
\hline
\end{tabular}

After the average temperature and relative humidity are obtained by averaging every 30 -second humidity and temperature reading for the 7 hours the test ran. The temperature is converted from Fahrenheit to Celsius using the following equation:

$$
T\left({ }^{\circ} \mathrm{C}\right)=\left(T\left({ }^{\circ} \mathrm{F}\right)-32\right) * \frac{5}{9}
$$

Then using the converted temperature and Table A-4 (Cengel, 2015), the saturation pressure (Psat@T) was determined through interpolation.

Table 5: Data from Table A-4 (Cengel, 2015)

\begin{tabular}{|r|r|}
\hline $\begin{array}{r}\text { Temperature } \\
\left({ }^{\circ} \mathbf{C}\right)\end{array}$ & $\begin{array}{r}\text { Saturation } \\
\text { Pressure } \\
(\mathbf{k P a})\end{array}$ \\
\hline 55 & 15.868 \\
\hline 60 & 19.947 \\
\hline 65 & 25.043 \\
\hline
\end{tabular}

$$
P_{\text {satoutlet }} \rightarrow 19.947 \mathrm{kPa}+\left(62.2^{\circ} \mathrm{C}-60^{\circ} \mathrm{C}\right) \frac{(25.043 \mathrm{kPa}-19.947 \mathrm{kPa})}{\left(65^{\circ} \mathrm{C}-60^{\circ} \mathrm{C}\right)}=22.21 \mathrm{kPa}
$$

The vapor pressure, $P_{v}$ was then determined using the relative humidity $(\phi)$ and the saturation pressure as inputs in the equation below.

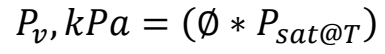

$$
\begin{aligned}
& P_{v}=22.21 \mathrm{kPa} * 0.121=2.68 \mathrm{kPa}
\end{aligned}
$$

The specific humidity is determined using the below equation (Cengel, 2015) whereas $P$ is the atmospheric pressure at Morgantown (101.325 kPa). 


$$
\begin{gathered}
\omega=\frac{\left(0.622 * P_{v}\right)}{\left(P-P_{v}\right)} \frac{\mathrm{kg} \text { water }}{\mathrm{kg} \text { dry air }} \\
\omega_{\text {outlet }}=\frac{(0.622 * 2.68)}{(101.325-2.68)}=0.01695 \frac{\mathrm{kg} \text { water }}{\mathrm{kg} \text { dry air }}
\end{gathered}
$$

\section{Results \& Discussion}

\subsection{Set 1 Results}

\subsubsection{Test 1, 2, 3}

The purpose of Test 1, 2, and 3 was to evaluate how size and shape variation of the banana chips impacted drying time and moisture loss. As well as, testing how the preparation effected the bananas. Test 3 was pretreated while Test 1 and 2 were not to provide a comparison. The pretreatment was done to evaluate if pretreating the food before dehydration effected drying time.

\subsubsection{Impact of Temperature on Rack Position}

Figures 3-5, show the impact of temperature at the outlet and the inlet in the dehydrator. In all of the tests, the inlet temperature is higher than the outlet temperature. The inlet sensor is positioned in the rack closest to the heating element, and therefore, created a hotter environment. The closer the position of the rack is to the heater the "hotter" the air is. The farther away the rack is from the heater the "colder" the dehydrators air. Since the banana chips are set on racks that stack on top of each other, and farther from the heater, each rack will experience a different temperature and drying environment. In order to eliminate these discrepancies, the racks are rotated every hour so that all of the banana chips get exposed to the different temperature environments of the dehydrator. 


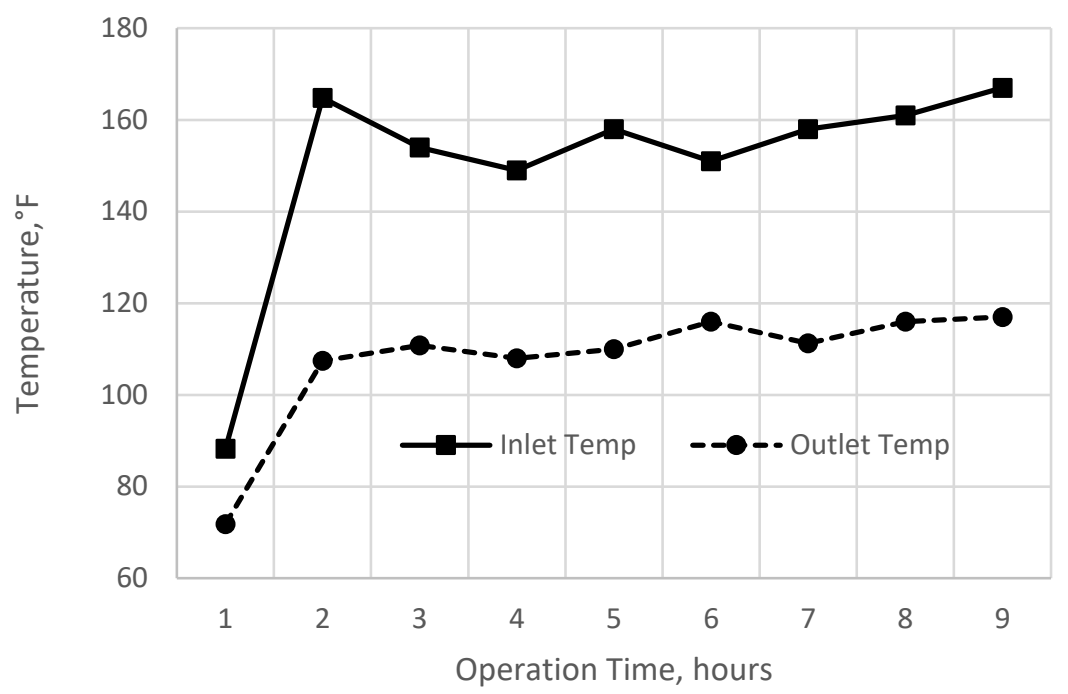

Figure 3: Variation of temperature through time at the outlet and inlet of the dehydrator measured in Test 1

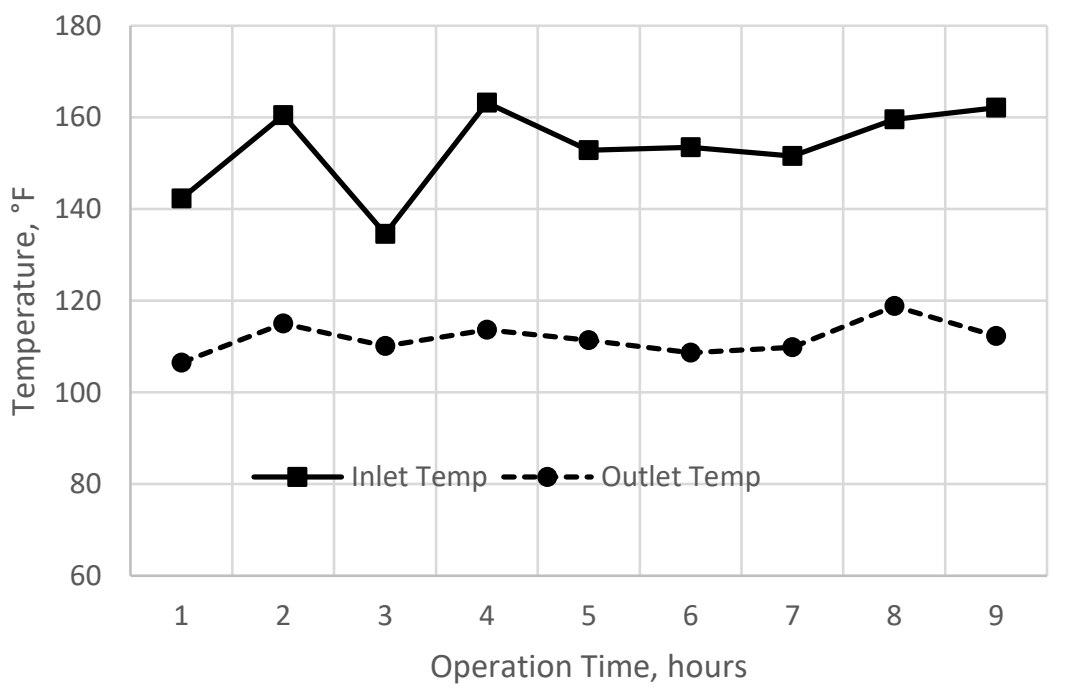

Figure 4: Variation of temperature through time at the outlet and inlet of the dehydrator measured in Test 2 


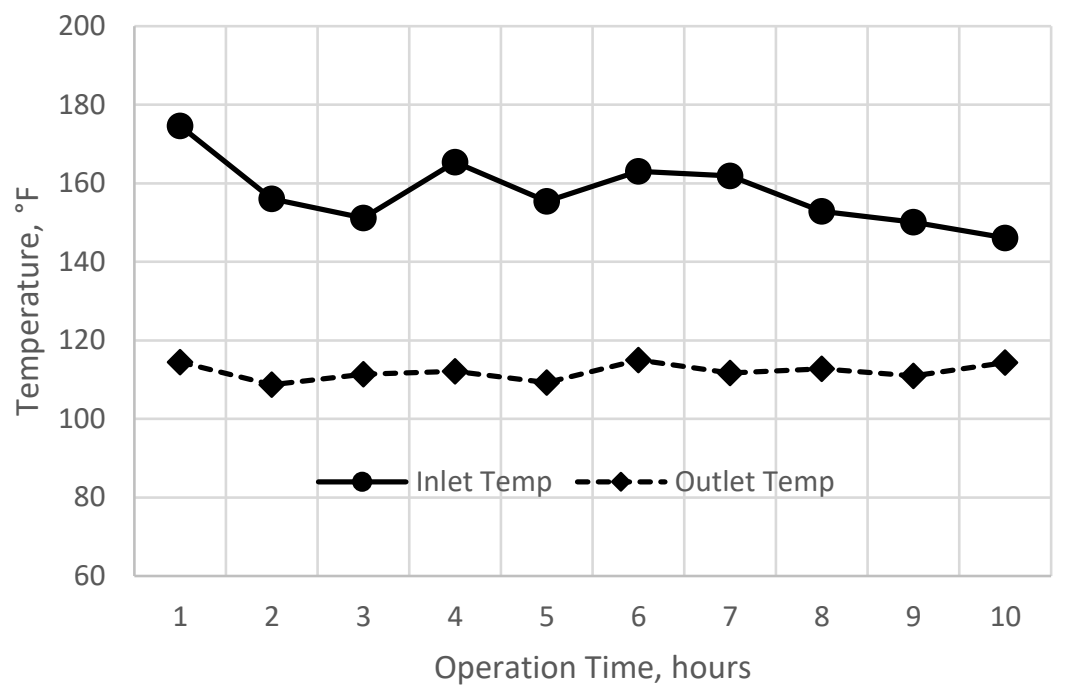

Figure 5: Variation of temperature through time at the outlet and inlet of the dehydrator measured in Test 3

\subsubsection{Impact of size of banana chips to drying time}

$\underline{\text { Test } 1}$

Most dried fruits contain between $20-25 \%$ of moisture (Timmermans, 2012). This test compared how long it took for the bananas to get dehydrated to a moisture content of $24 \%$. The thinner cut bananas dehydrated faster and contained less moisture content than the thicker cut bananas (Figure 6). The thin cut bananas reached $24 \%$, between hour four and five which was faster than any other cut. The bananas that lost the smallest amount of moisture in the test was the circle thick cut which reached $24 \%$ moisture content in the eighth hour. Also, in this test, the thicker the banana cut was the higher the original moisture content.

\section{$\underline{\text { Test } 2}$}

This test was run for eight hours. There were four different cuts of bananas: thick circle, thin circle, thick diagonal, and thin diagonal. In this test, the thin circle and thin diagonal lost the most moisture content by the end of the test (Figure 7). Circle thin reached a moisture content of $24 \%$ between the fifth and sixth hours; faster than any other cut. The cut that lost the smallest amount of moisture content was the diagonal thick cut bananas, which reached $24 \%$ total moisture content at hour 9 . 


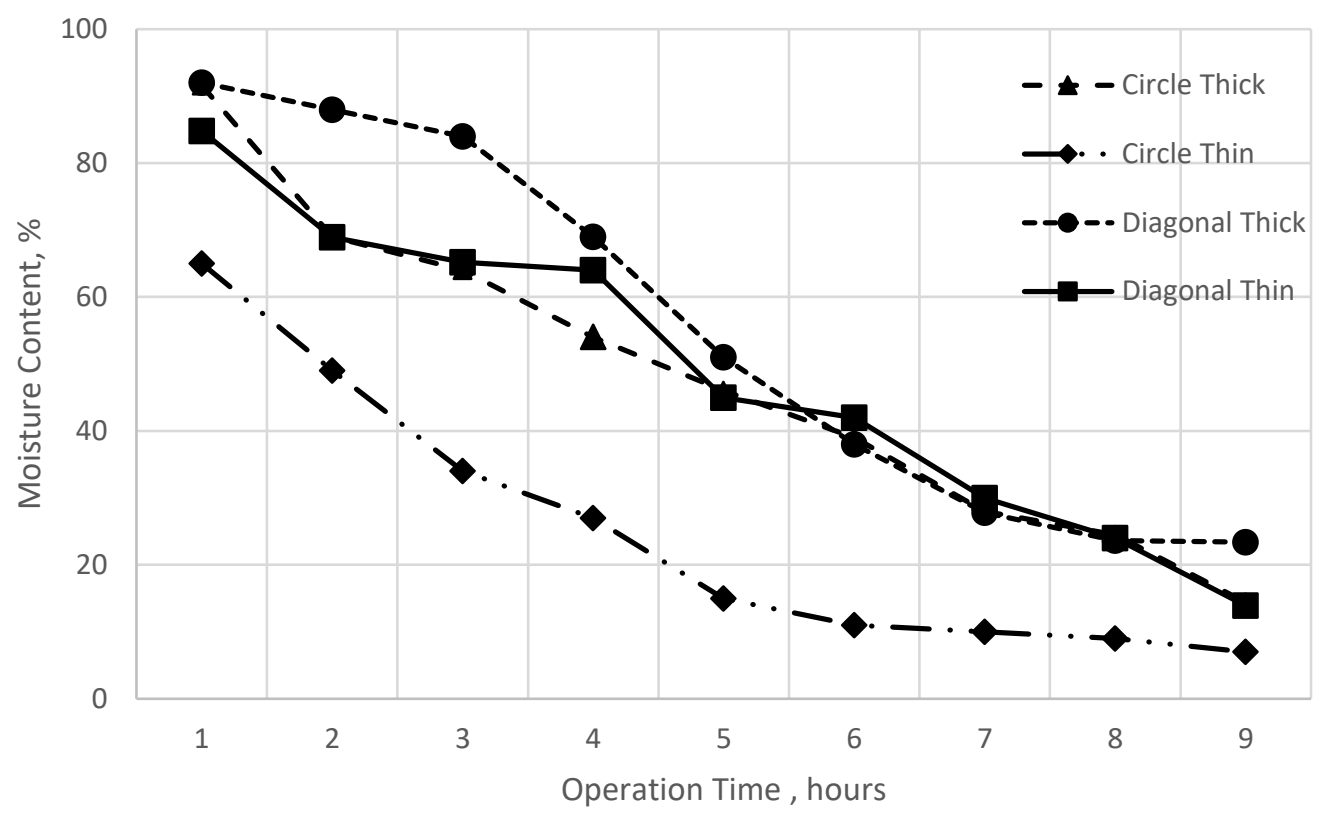

Figure 6: Effect of time on the moisture content of different sized banana chips measured in Test 1

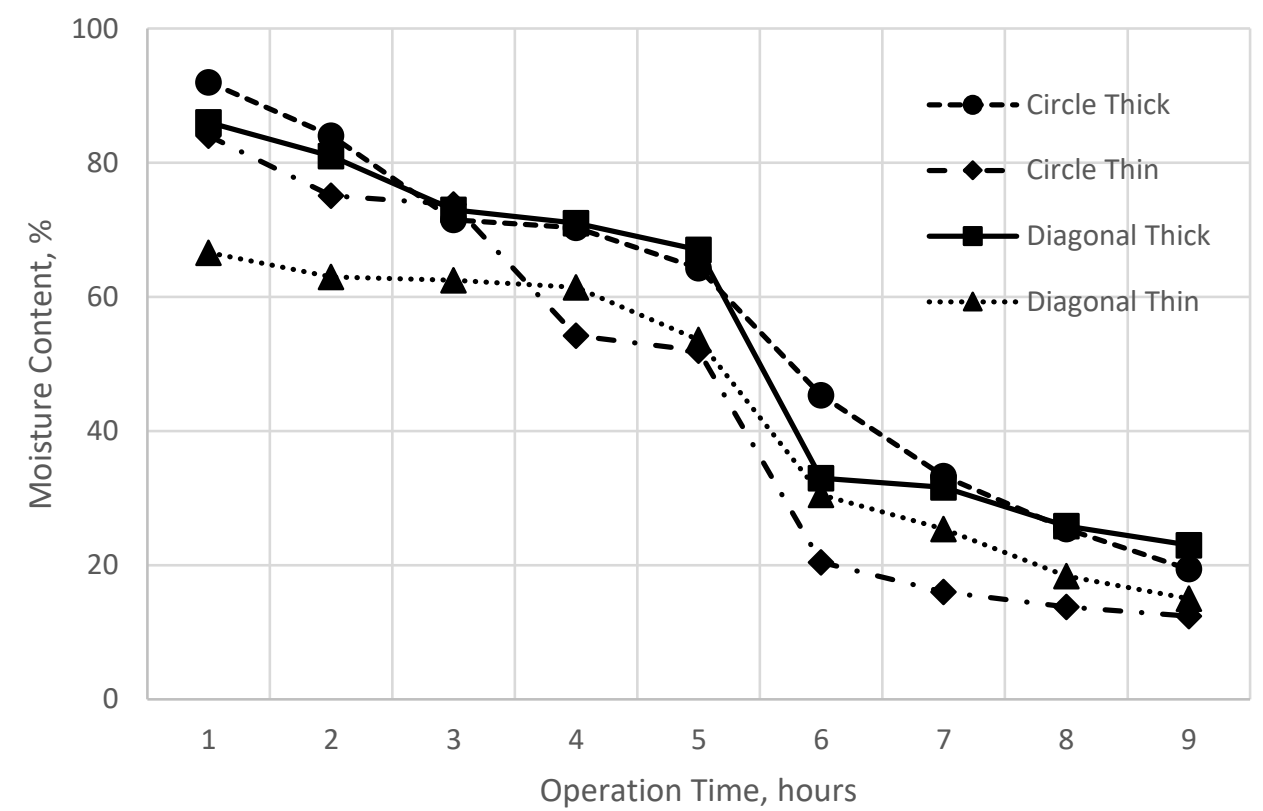

Figure 7: Effect of time on the moisture content of different sized banana chips measured in Test 2 


\section{Test 3}

In this test, the bananas were pretreated with lemon juice water. The bananas were cut into four different sizes (circle thin, circle thick, diagonal thick, diagonal thin) and dehydrated as well. Here the thin bananas and thick bananas show a more distinct separation in Figure 8 as they are losing moisture through this ten-hour test. Diagonal thin achieved $24 \%$ moisture content first between the fifth and sixth hour. Circle thin reached $24 \%$ between the sixth and seventh hour. Diagonal thick lost the least amount of total moisture at the end of the test, reaching $24 \%$ total moisture content in hour ten. While Circle thick achieved $24 \%$ between hour nine and ten, reaching a total moisture content of $22 \%$ at the end of the test.

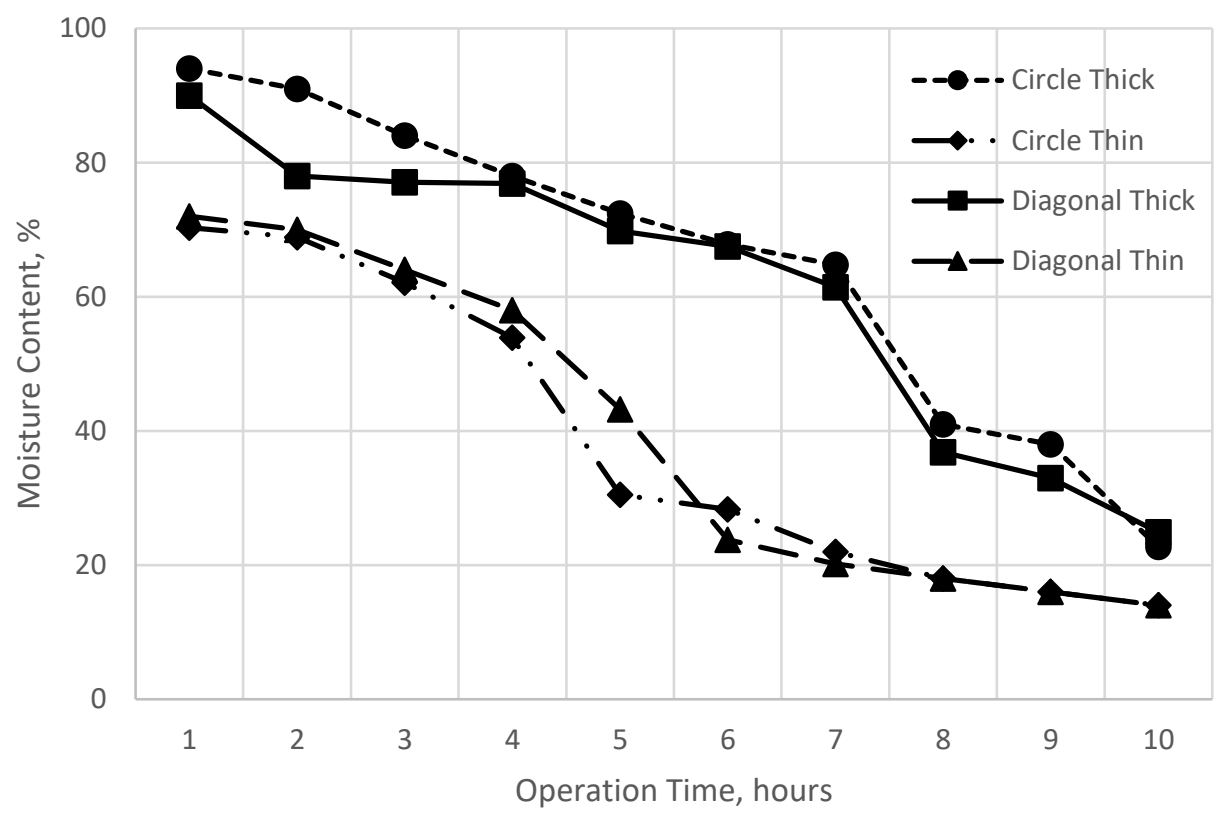

Figure 8: Effect of time on the moisture content of different sized banana chips measured in Test 3

\section{Summary}

In Figures 6-8, the thicker sliced bananas took longer to dehydrate to $<25 \%$ moisture content than the thinly sliced bananas. The thicker sliced bananas also carried a higher initial moisture content in hour one than the thinly sliced bananas. The thicker the slice the more mass and 
more moisture it contains. The more moisture that the banana chips carry, the more moisture that has to be removed, and the longer the drying time needed.

\subsubsection{Impact of Pre-treatment}

The banana chips in Test 3 were pretreated with the lemon juice and water mixture before dehydration. As shown in Figure 8, the total time needed for dehydrating banana chips in Test 3 was 10 hours. In comparison, the dehydrating process in Test 1 and 2 takes a total of 9 hours. The moisture added during the pretreatment process did not add too much moisture to the banana chips from comparing Figure $8^{\prime} \mathrm{s}$ original moisture content to the original moisture content of Figure 6 and 7. The lemon juice pretreatment is used to add flavor, extend shelf life, and to also aid in keeping the banana chips color by preventing extensive drying. The pretreatment became a barrier for the moisture removal of the thicker sliced banana chips, when compared to the banana chips of the same shape in Test 1 and 2, resulting in a longer drying time.

\subsubsection{Test 4}

The racks in Test 4 were not rotated so that a measurement of how much moisture was removed from the bananas at a "hot", "warm", and "cool" air scenario could be assessed. The hottest ("hot") temperature was the bottom rack, the middle rack was less hot("warm"), and the top rack was the rack with the lowest temperature("cool") (Figure 9). The bananas in this test were cut circle thin and pretreated with lemon juice water. The moisture removed was calculated using the difference in weight loss of each banana rack each hour.

Overall, the banana chips in the bottom rack with the highest temperature lost more moisture than those in the top rack where the temperature is relatively low (Figure 10 and Table 6). The bottom rack lost moisture at an average rate of 0.46 grams/sec. The "cold" environment (top rack) lost the least amount of moisture at the slowest rate of 0.40 grams $/ \mathrm{sec}$ (Table 6). It can be concluded that the hotter the air temperature, the more moisture is removed. This is due to the lower relative humidity observed 
at a higher temperature. The higher temperature, allowed for more moisture to be held in the air as it was moving through the dehydrator.

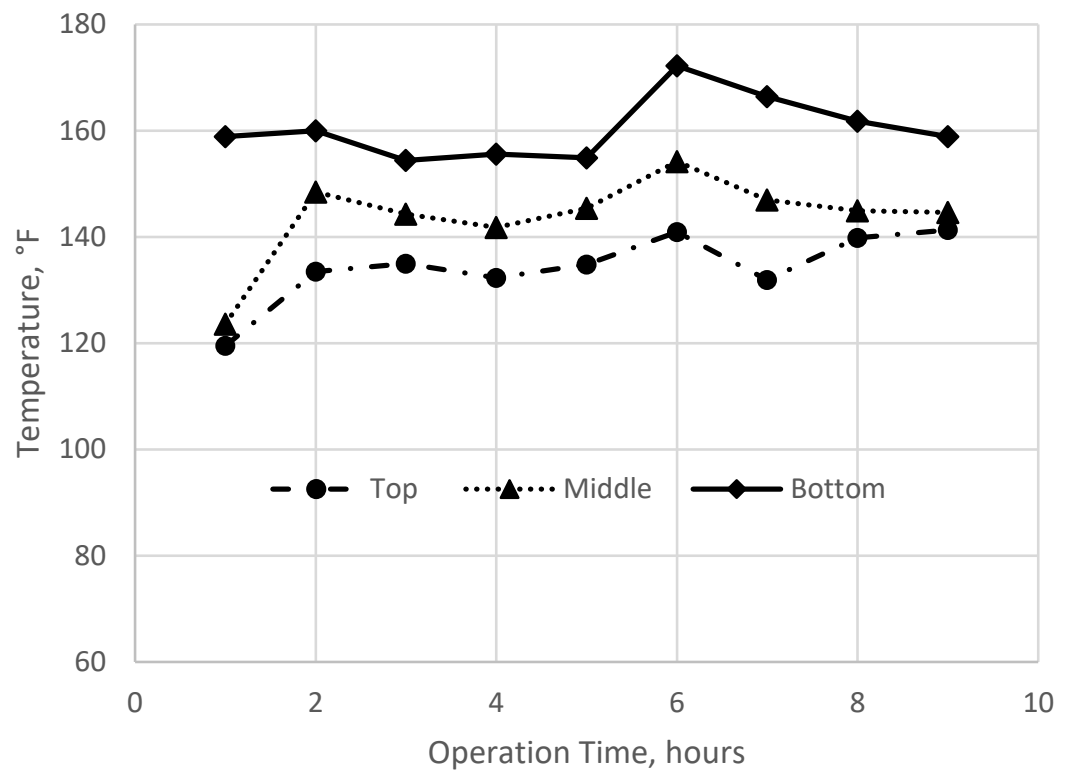

Figure 9: Variation of temperature through time and the Top, Middle, and Bottom Racks measured in Test 6

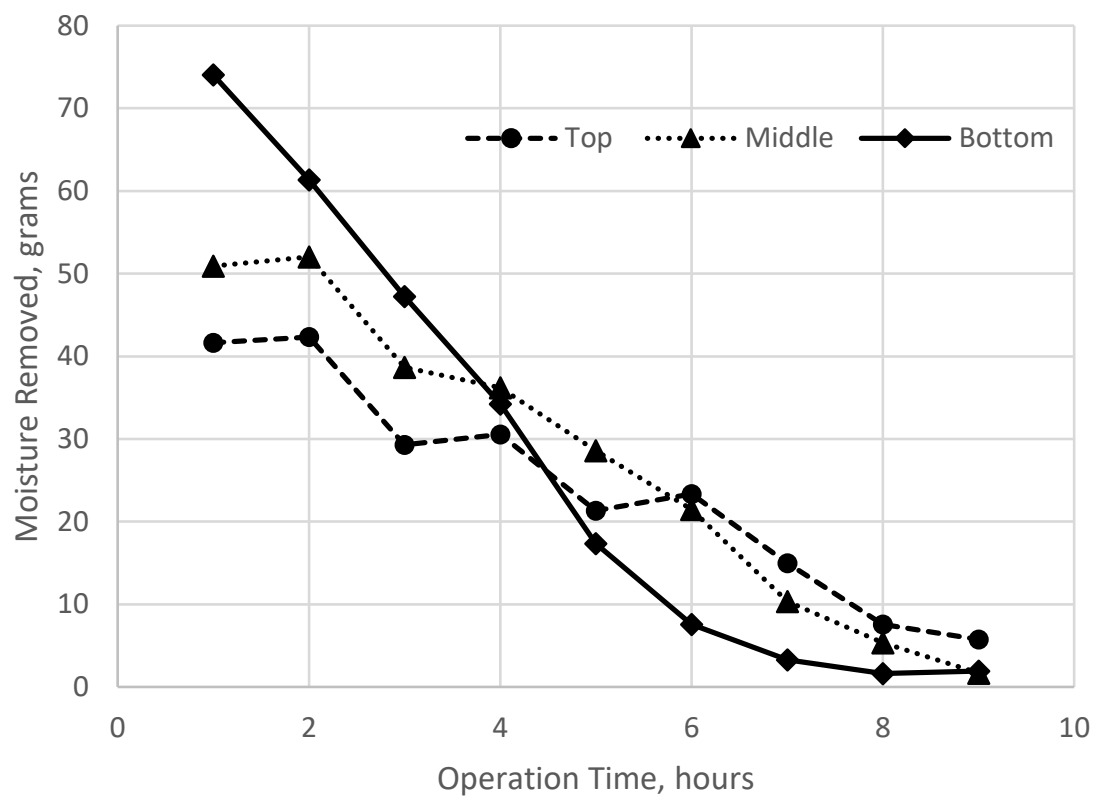

Figure 10: Effect of moisture removed (grams) on time of Top, Middle, and Bottom Racks Test 4 
Table 6: Average Temperature and Moisture Removal Rate for each rack position in Test 4

\begin{tabular}{|l|l|l|}
\hline Rack Position & Moisture Removed, grams/sec & Average Temperature, ${ }^{\circ} \mathrm{F}$ \\
\hline Top & 0.40 & 134.33 \\
\hline Middle & 0.45 & 143.81 \\
\hline Bottom & 0.46 & 160.34 \\
\hline
\end{tabular}

\subsubsection{Humidity}

The humidity decreases through time on all three tests. In Test 1, 2, and 3 both the top and bottom data loggers showed the trend of humidity decreasing over time. All of the indentions or drastic declines at every hour (two are shown circled in red in Figure 11) where racks were removed from the dehydrator to take moisture content and mass measurement. The black curve represents the temperature, while the blue curve represents the humidity. The humidity percentage tends to be higher for the bottom data logger, which is located in the lowest rack near the heater, at the start of testing in comparison to the top data logger. The temperature measured by the bottom data logger is higher than the top data logger. The relative humidity at the end of the test for the bottom and the top data loggers are between $2-5 \%$.

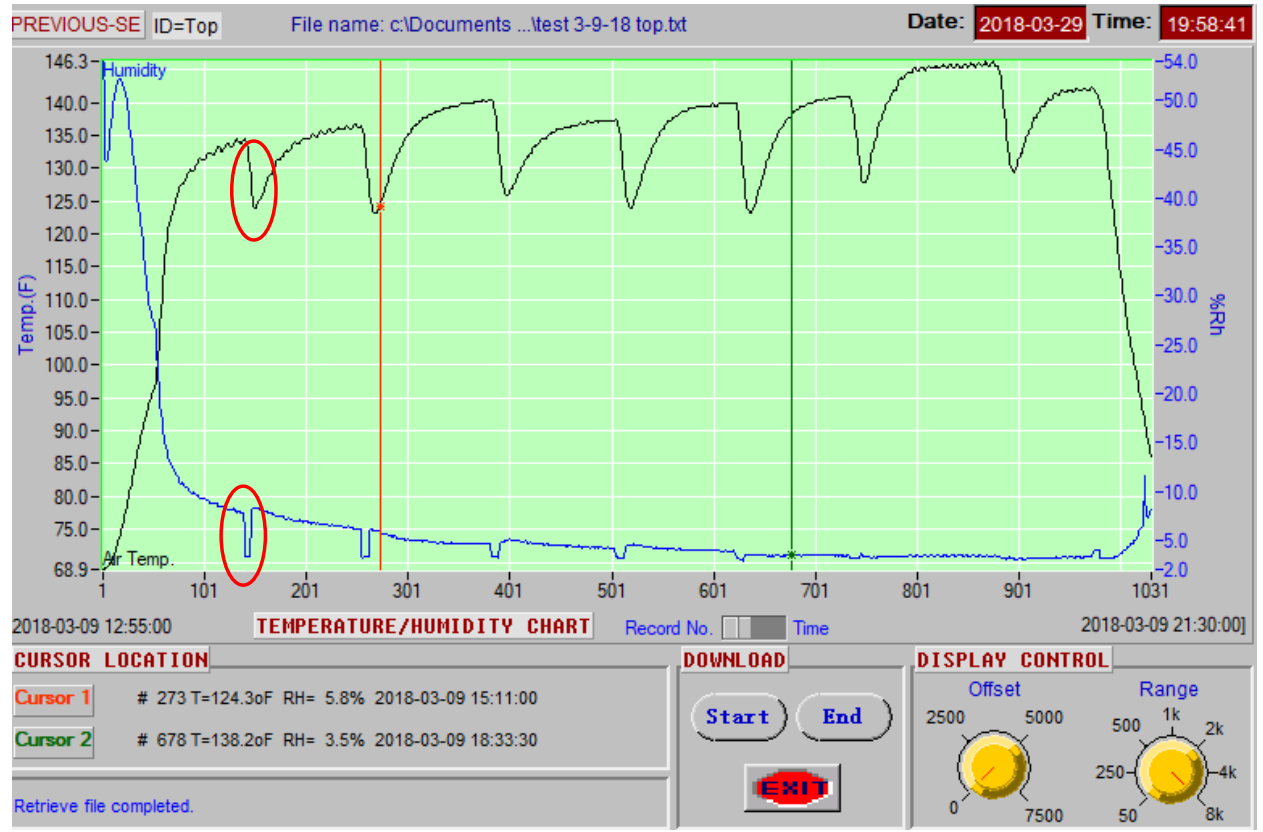

Figure 11: Test 1 humidity reading top logger 


\subsection{Set 2 Results}

This set of tests were used to examine the effect of the environmental conditions, including humidity and air speed on the dehydration process. There was a total of 12 tests run. A test was run in high, medium, and low fan air speeds for each environmental setting (refer to Table 2). There were four environmental settings (refer to Table 3). Each of the environmental settings is represented by specific case names.

Two sensors were used to collect temperature and relative humidity in the system for each test. One was installed in the chamber where the bananas were being dehydrated and the other was installed at the outlet. In the data, the chamber sensor information is denoted as "bottom", indicating the sensor located at the most bottom part of the dehydration system. The second sensor located at the outlet of the dehydration system data was denoted as "top", meaning the sensor at the most top part of the dehydration system.

\subsubsection{Impact of Air Velocity on Moisture Weight Lost}

\section{Case 1 w/o Air Conditioning}

Case 1 tests were conducted in a building at an ambient temperature higher than $75^{\circ} \mathrm{F}$. The medium speed test has lost the most moisture weight at $92 \%$, the low-speed test lost $90 \%$ moisture weight, and the lowest moisture weight lost was from the high fan speed test at $89 \%$. The relative humidity and temperature were not controlled in this case and it contributed to the percent of the moisture weight lost pattern. There was no clear pattern established between the different air speeds and the percent of moisture that was lost.

Table 7: Moisture weight lost percentage in Case 1

\section{\begin{tabular}{l|l} 
Case 1 & Percent of Moisture Weight Lost
\end{tabular}}




\begin{tabular}{|l|r|}
\hline High-Speed Test & $89 \%$ \\
\hline Medium Speed Test & $92 \%$ \\
\hline Low-Speed Test & $90 \%$ \\
\hline
\end{tabular}

\section{Case 2 w/Air Conditioning}

Case 2 tests were conducted in an air-conditioned environment where the ambient temperature was $<75^{\circ} \mathrm{F}$. For Case 2 , the high-speed fan test removed more moisture released from the bananas, removing approximately $92 \%$ of moisture weight contained in the bananas. The Middle speed removed approximately $91 \%$ of total moisture weight and the lower speed removed approximately $90 \%$.

Table 8: Moisture weight lost percentage in Case 2

\begin{tabular}{|l|r|}
\hline \multicolumn{1}{|c|}{ Case 2 } & Percent of Moisture Weight Lost \\
\hline High-Speed Test & $92 \%$ \\
\hline Medium Speed Test & $91 \%$ \\
\hline Low-Speed Test & $90 \%$ \\
\hline
\end{tabular}

\section{Case 3 Steam Additive}

In Case 3, the higher the fan speed the more moisture was lost. The low-speed test lost $80 \%$ of moisture weight in comparison to the $87 \%$ water weight loss of the medium speed test, and $91 \%$ moisture weight lost on the low-speed fan test. This Case had the lowest overall moisture weight lost percentage. Adding steam increased the relative humidity and moisture content of air entering the dehydrator. By increasing the relative humidity, the moisture content of the air in the dehydrator also increased. Instead of conditioned air dehydrating bananas, the air was moist. The vapor density of the air had increased, decreasing the amount of moisture the bananas can dissipate into the air before it reaches its saturation point. This decrease leads to a lower amount of moisture weight being removed through the dehydration system. 
Table 9: Moisture weight lost percentage in Case 3

\begin{tabular}{|l|r|}
\hline \multicolumn{1}{|c|}{ Case 3 } & Percent of Moisture Weight Lost \\
\hline High-Speed Test & $91 \%$ \\
\hline Medium Speed Test & $87 \%$ \\
\hline Low-Speed Test & $80 \%$ \\
\hline
\end{tabular}

\section{Case 4 Outside-Ambient air without air conditioning}

In Case 4, the speed of the fan does not have as much of an effect in dehydrating the bananas, and the low-speed test removed more moisture weight from bananas than the high and medium speed test. Since the test was conducted in the outside ambient air environment, the temperature and relative humidity of air throughout the test cannot be controlled. The uncontrollable environment has contributed to the irregular moisture weight lost pattern.

Table 10: Moisture weight lost percentage in Case 4

\begin{tabular}{|l|r|}
\hline \multicolumn{1}{|c|}{ Case 4 } & Percent of Moisture Weight Lost \\
\hline High-Speed Test & $89 \%$ \\
\hline Medium Speed Test & $89 \%$ \\
\hline Low-Speed Test & $90 \%$ \\
\hline
\end{tabular}

\section{Summary}

In Case 1 and Case 4, the temperature and relative humidity were not controlled, and the speed of the fan had a negligible effect on moisture weight lost. While in Case 2 and Case 3, where the relative humidity and temperature were controlled by air conditioning, increasing fan speed removed more moisture from the banana chips.

\subsubsection{Specific Humidity}

Measuring the specific humidity allows for the four cases to be compared on the basis of how much water is leaving per kg of dry air. Tables 11 and 12, display the calculated specific humidity of each of the four environments, using the average relative humidity and the average temperature from the outlet (top) and dehydrating chamber (bottom) sensors. In Case 1, where there was no air conditioning, the 
range of the specific humidity is $0.015-0.021 \mathrm{~kg} \mathrm{H}_{2} \mathrm{O} / \mathrm{kg}$ dry air. Case 2, where there was air conditioning, the range of the specific humidity $0.010-0.013 \mathrm{~kg} \mathrm{H}_{2} \mathrm{O} / \mathrm{kg}$ dry air. Case 3 , where there was air conditioning, the range of the specific humidity $0.027-0.094 \mathrm{~kg} \mathrm{H}_{2} \mathrm{O} / \mathrm{kg}$ dry air. Case 4 , where there was no air conditioning, the range of the specific humidity $0.016-0.021 \mathrm{~kg} \mathrm{H}_{2} \mathrm{O} / \mathrm{kg}$ dry air.

The relative humidity measured at Case 1 and Case 4 are comparable. Both of their environments have no air conditioning involved and the ambient conditions could have created a similar allowance of how much water is leaving per kg of dry air. Case 3 has the highest range of specific humidity, which aligns with its environment of higher humidity due to the addition of steam. The steam additive increased the amount of water leaving the system per kg of air. The relative humidity measured in Case 2 was the lowest, which was due to the air conditioning beingg on. The air conditioning not only lowers the temperature, but it lowers the relative humidity as well. The environmental relative humidity does, in fact, play a role in the dehydration process. It allowed for the variation in relative humidity to display itself in the specific humidity of the air flowing inside and leaving the dehydrator.

\section{Case1\&2}

Table 11 summarizes the average relative humidity and the average temperature in the dehydrator of each test ran in Case $1 \& 2$, as well as the resulting specific humidity of each test calculated through the Excel sheet from those measured values. The specific humidity measured at the bottom for Case 1 and Case 2 are all higher than that measured by the top sensors from the same test. As the hotter temperature flows over the bottom rack, the more moisture is expelled into the air. At the top of the system where the temperature is cooler, less moisture is being expelled from the banana chips, causing the specific humidity to be lower when only accounting for the banana chips on the top rack and removing the moisture carried from the racks below it.

\section{Case3\&4}


Table 12 summarizes the average relative humidity and the average temperature in the dehydrator of each test ran in Case $3 \& 4$, as well as the resulting specific humidity of each test calculated through the Excel sheet from those measured values. All of the bottom sensors for Case 3 and 4 are higher in specific humidity than the top sensors from the same test. Case 3 and 4 follow a similar pattern to Case 1 and 2, the hotter the temperature is the more moisture is expelled.

Table 11: Avg. Relative Humidity, Avg. Temperature, and Specific Humidity of Case 1 and Case 2 from the top and bottom sensors of the dehydrator system

\begin{tabular}{|l|l|l|l|}
\hline Test & Avg. Relative Humidity & Avg. Temperature & $\begin{array}{l}\text { Specific Humidity } \\
\text { \% }\end{array}$ \\
\hline Case 1 & & & \\
\hline High Speed Bottom & 11.55 & 150.52 & 0.019 \\
\hline High Speed Top & 12.13 & 144.05 & 0.017 \\
\hline Middle Speed Bottom & 10.69 & 149.01 & 0.021 \\
\hline Middle Speed Top & 12.93 & 140.19 & 0.017 \\
\hline Low Speed Bottom & 12.65 & 143.24 & 0.017 \\
\hline Low Speed Top & 15.09 & 130.92 & 0.015 \\
\hline Case 2 & & & \\
\hline High-Speed Bottom & 8.13 & 148.52 & 0.013 \\
\hline High Speed Top & 8.01 & 145.02 & 0.011 \\
\hline Middle Speed Bottom & 8.43 & 148.28 & 0.013 \\
\hline Middle Speed Top & 8.51 & 140.53 & 0.011 \\
\hline Low Speed Bottom & 10.52 & 139.81 & 0.013 \\
\hline Low Speed Top & 9.73 & 132.38 & 0.010 \\
\hline
\end{tabular}

Table 12: Avg. Relative Humidity, Avg. Temperature, and Specific Humidity of Case 3 and Case 4 based on average data from the top and bottom sensors of the dehydrator system

\begin{tabular}{|l|l|l|r|}
\hline Test & \multicolumn{1}{|l|}{$\begin{array}{l}\text { Avg. Relative Humidity } \\
\text { \% }\end{array}$} & $\begin{array}{l}\text { Avg. Temperature } \\
\text { \% }\end{array}$ & \multicolumn{1}{l|}{ Specific Humidity } \\
\hline Case 3 & & & $\mathrm{kg} \mathrm{H}_{2} \mathrm{O} / \mathrm{kg}$ Dry Air \\
\hline High Speed Bottom & 22.29 & 143.34 & 0.3139 \\
\hline High Speed Top & 30.27 & 126.33 & 0.02724 \\
\hline $\begin{array}{l}\text { Medium Speed } \\
\text { Bottom }\end{array}$ & 60.35 & 134.54 & 0.07225 \\
\hline Medium Speed Top & 57.23 & 124.62 & 0.05083 \\
\hline Low Speed Bottom & 83.45 & 131.13 & 0.09391 \\
\hline Low Speed Top & 81.48 & 122.82 & 0.07058 \\
\hline Case 4 & & & \\
\hline High Speed Bottom & 13.38 & 147.66 & 0.02061 \\
\hline High Speed Top & 12.87 & 140.42 & 0.01637 \\
\hline
\end{tabular}




\begin{tabular}{|l|r|r|r|}
\hline $\begin{array}{l}\text { Medium Speed } \\
\text { Bottom }\end{array}$ & 13.96 & 147.79 & 0.0216 \\
\hline Medium Speed Top & 18.21 & 131.64 & 0.0186 \\
\hline Low Speed Bottom & 13.88 & 146.40 & 0.02075 \\
\hline Low Speed Top & 17.49 & 130.08 & 0.01711 \\
\hline
\end{tabular}

\subsubsection{Impact of Air Velocity on Drying Time}

\section{General Trendlines}

\section{Case 1}

In Case 1 , the high and medium speed both took seven hours to reach less than $25 \%$ moisture, while the low speed took 8 hours. The high speed lost the most moisture per hour at about $9.6 \% / \mathrm{hr} .$, while medium speed lost $8.8 \% / \mathrm{hr}$., and low speed lost $6.1 \% / \mathrm{hr}$.

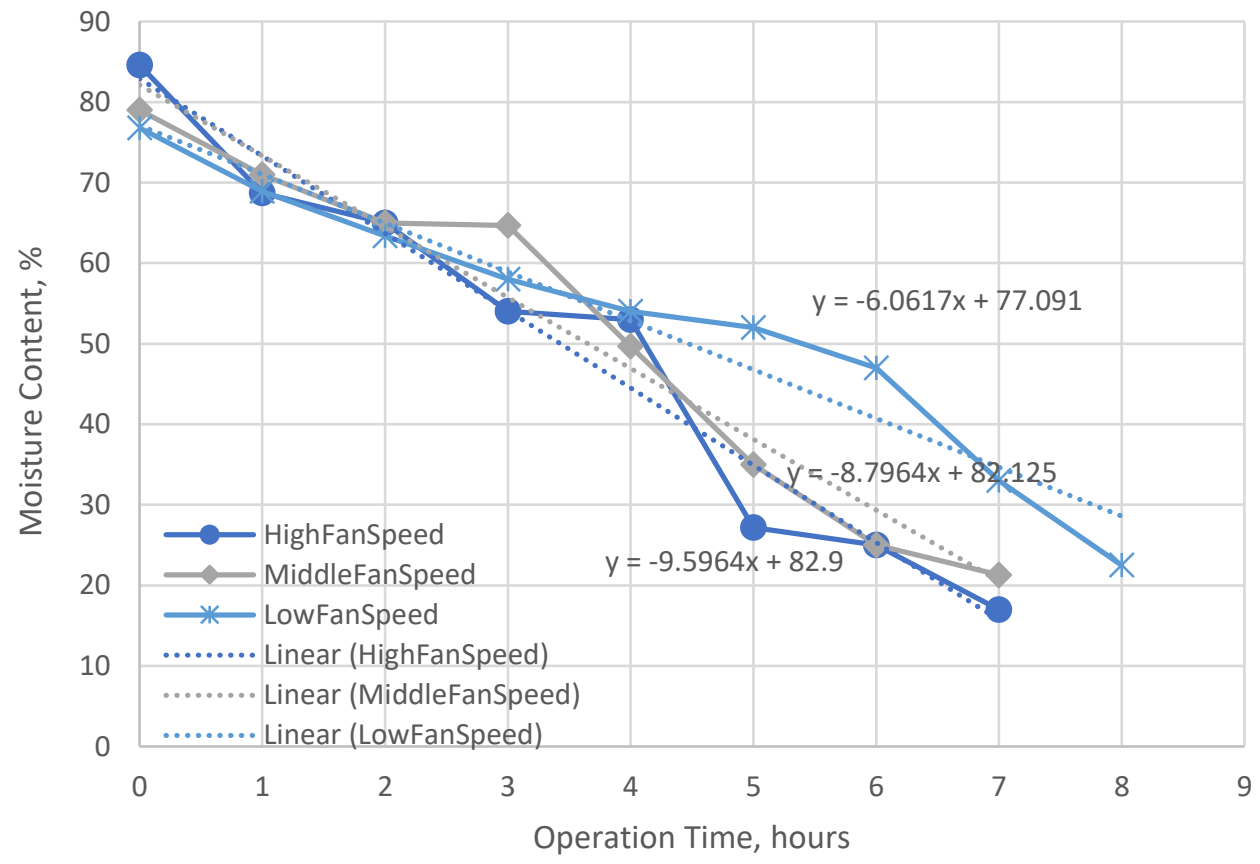

Figure 12: Variation of moisture content in relation to operating time in Case 1

\section{Case 2}

In Case 2, the high-speed and middle-speed tests both took six hours to reach less than $25 \%$

moisturized, while the low-speed test took eight hours. The trend line equations in Figure 13, showed 
that there was more moisture lost in an hour at the high speed at about $9.1 \%$ of moisture per hour. The percentage lost per hour decreases as the speeds decrease.

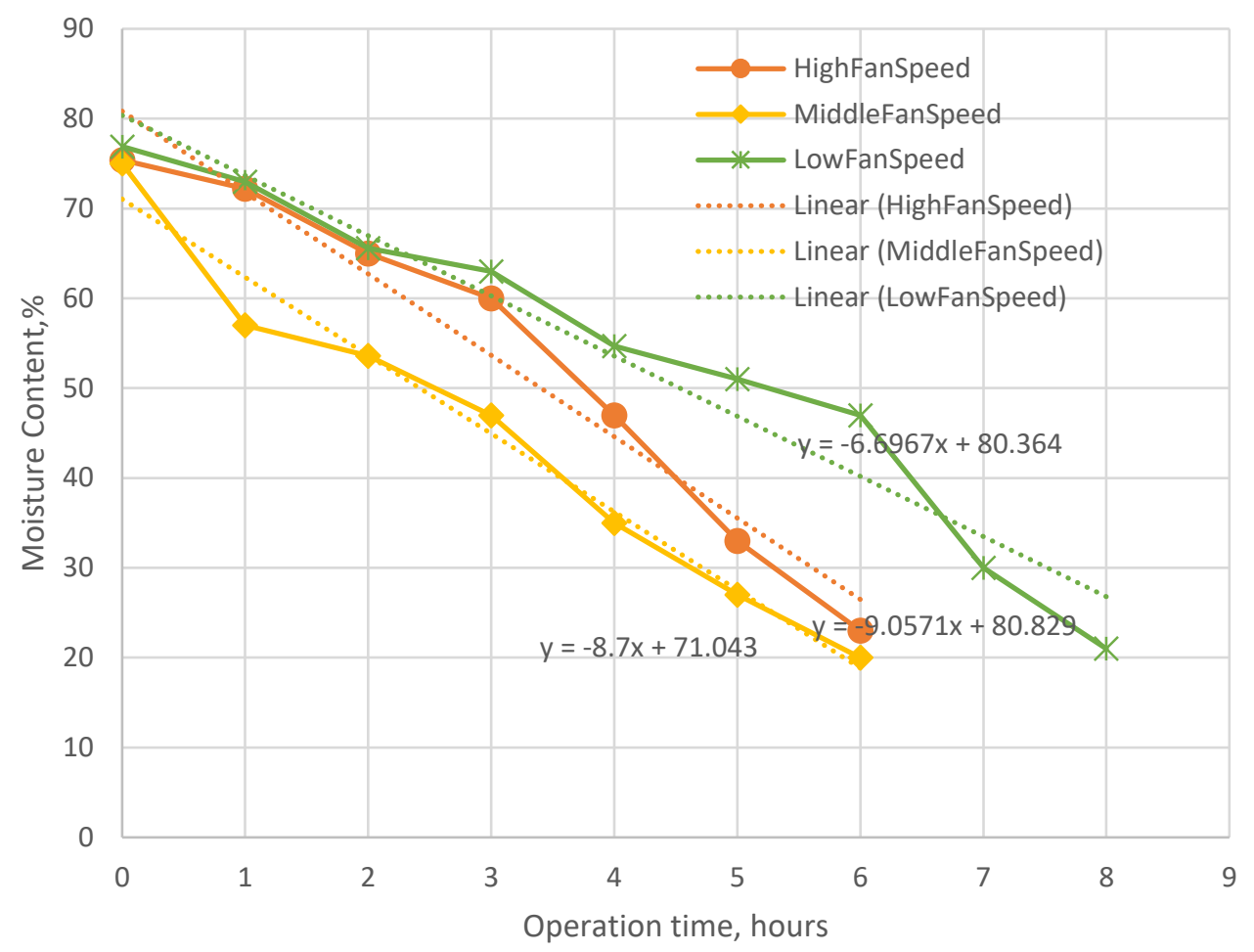

Figure 13: Variation of moisture content in relation to operating time in Case 2

\section{Case 3}

During Case 3 tests, the high and medium tests both reached less than 25\% moisture at six hours. While the low-speed test took seven hours. The high speed lost more moisture per hour than the medium and low speeds, losing about $9.8 \%$ moisture/hr. Compared to the Case 2 environment, this case removed more moisture per hour than the other cases in the high and medium speeds, seeing that the moisture content was higher because of the added steam, the increase in moisture removed correlates to the increase in relative humidity. The low speed, however, lost less moisture per hour than in the other two tests. It still dehydrated in the same number of hours in Case 2 but less moisture was removed per hour than in environments without the steam additive. 
During the low-speed test, a lot of the water condensed in the dehydration chamber due to the lack of air speed to carry the moist air out (Appendix B for a photo of condensation). With the changes in temperature and the low air flow, there was a significant amount of condensation. This condensation could have attributed to the lower moisture removal since the air achieved a relative humidity of $99 \%$ during the test, and therefore could not hold any more moisture to remove out of the system-causing the bananas to retain more moisture or for the moisture to be condensed.

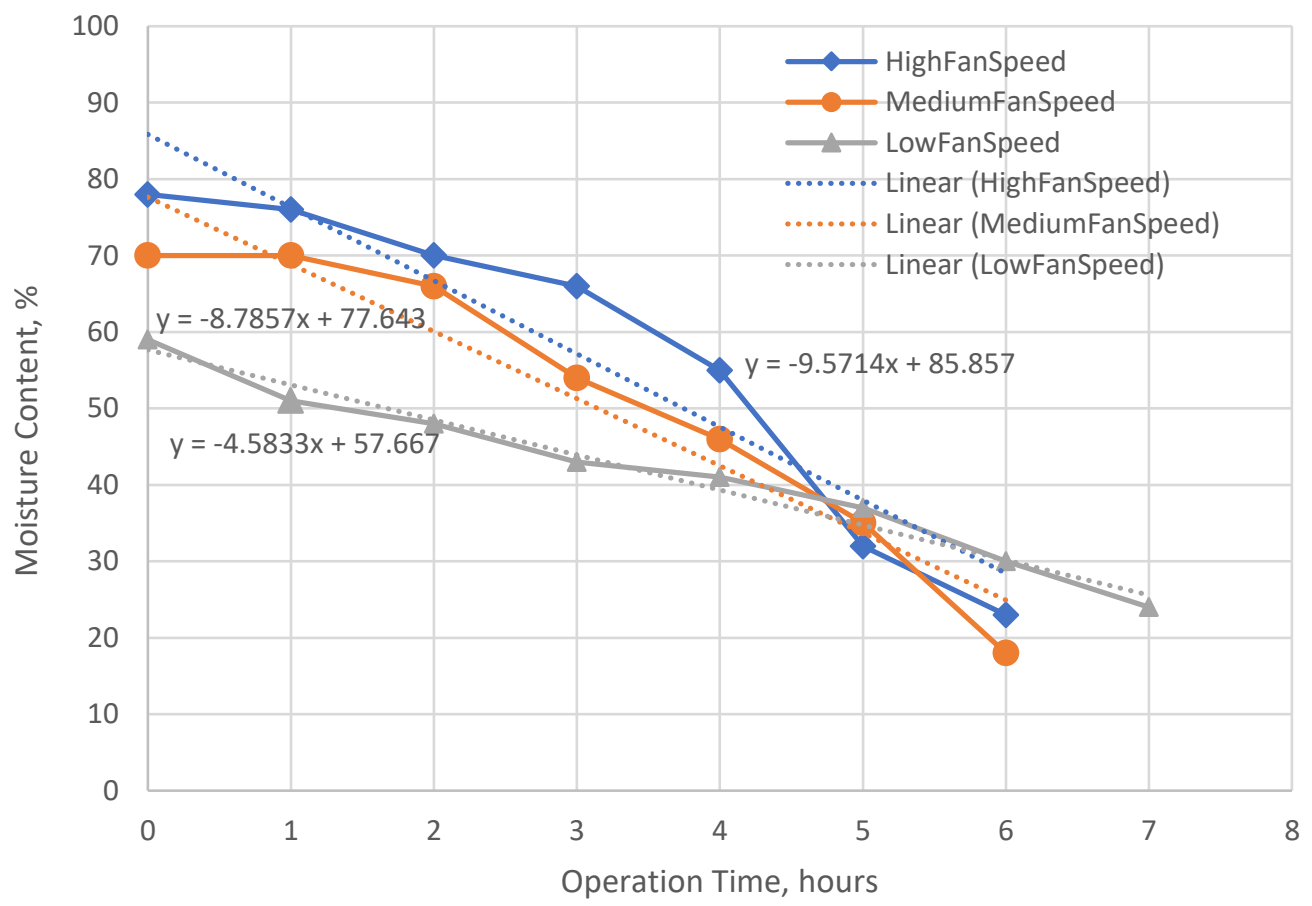

Figure 14: Variation of moisture content in relation to operating time in Case 3

\section{Case 4}

In Case 4 , the medium and high speed fan tests both reached a moisture content of less than $25 \%$ in five hours, whereas the low-speed test took six hours. The bananas were more dehydrated at high fan speed than those of the medium tests and therefore removed more moisture in an hour than that of the medium and low speed tests, removing about $9.5 \%$ of moisture per hour. In comparison, the medium speed case $7.9 \% / \mathrm{hr}$. which is similar to the $7.8 \% / \mathrm{hr}$. removed at low speed. 


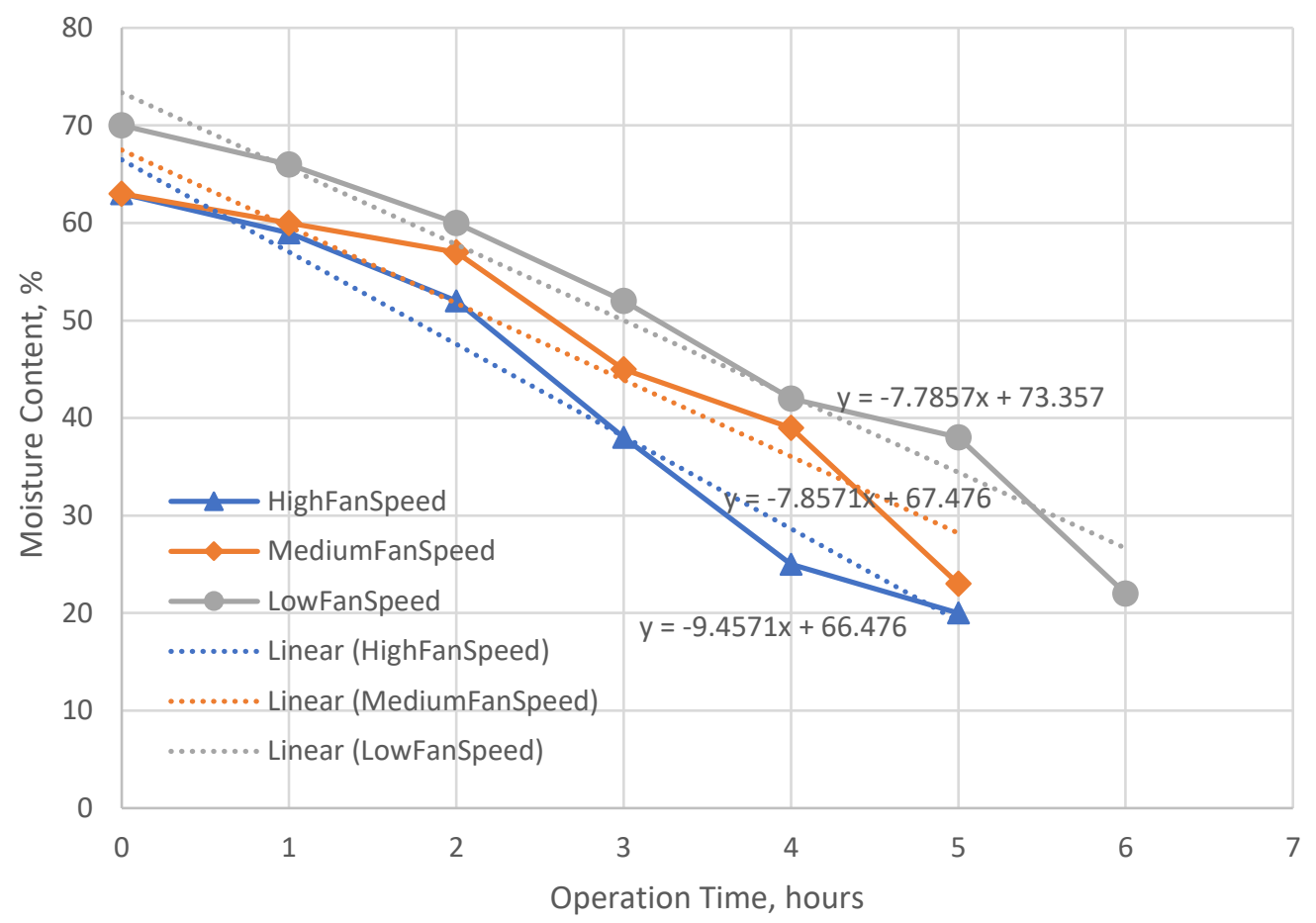

Figure 15: Variation of moisture content in relation to operating time in Case 4

\section{Summary}

In general, the high fan speed tests removed more moisture per hour than the medium and low speed tests in all Cases. Working in an environment with no air conditioning inside of a building (Case 1) caused the bananas to take the longest to dehydrate, but when not air-conditioned outside the building (Case 4) the bananas took the shortest amount of time to dehydrate. The circulation of air, changes in humidity, and temperature throughout Case 4 allowed for the bananas to dehydrate faster than in an inside of a building environment where the air had less circulation in the space and remained at an elevated temperature and humidity. Case 1, 2, and 3 tests took between six to eight hours to dehydrate the bananas. In Case 2, the low speed took eight hours to dehydrate but removed more moisture per hour than in Case 3 low-speed test. The medium and high fan speed tests of Case 3 removed more moisture than in Case 2, which is expected since more moisture is added to the test through the steam. 


\section{Segmented Regression}

In order to more closely relate the relationship between air velocity and moisture loss, each Case was graphed according to the speed of the fan. Segmented regression was applied per operating hours. The segmented regression only compared the moisture loss to operation hours up to the shortest dehydration time at each speed. In the high and middle fan speed that was 5 hours, and in the low fan speed that was 6 hours. The high and medium fan speeds were segmented in between the hours of 0-2 and 2-5 hours. The low-speed fan tests were segmented between hours of $0-2,2-4$, and $4-6$. In each of the graphs, the slopes for each of the segmented equations generated by the segmented time frames were averaged to create a generalized equation to represent the relationship of moisture loss to time.

In the low fan speed tests of Case 1-Case 4, hours 0-2 and 4-6 both achieved the slope of $-5.71 \% / \mathrm{hr}$. While in hours $2-4$ the slope was $-5.66 \% / \mathrm{hr}$., having a lower moisture loss than in the other two time segments.

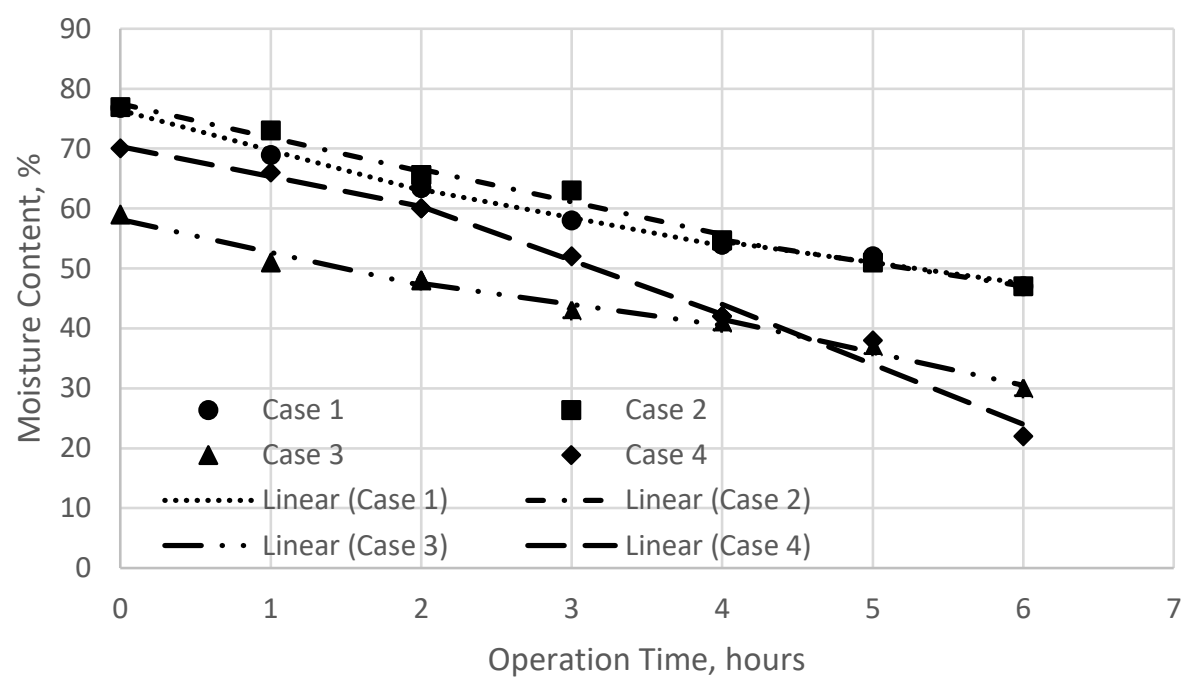

Figure 16: Low fan speed impact of moisture loss in relation to time graph Case 1-4

In the middle-speed fan tests the hours were segmented from hours $0-2$, and 2-5. In between hours 0-2 the slope was less than the hours of $2-5$. The slope increased from $-5.675 \% / \mathrm{hr}$ to $-10.145 \% / \mathrm{hr}$ in hours 2-5. 
Table 13: Low-speed Case 1-4 segmented regression slopes and average

\begin{tabular}{|l|l|l|l|}
\hline $\begin{array}{l}\text { Operating } \\
\text { Hours }\end{array}$ & $\mathbf{0 - 2}$ & $\mathbf{2 - 4}$ & $\mathbf{4 - 6}$ \\
\hline Case 1 & $-6.7 \% / \mathrm{hr}$ & $-4.7 \% / \mathrm{hr}$ & $-3.5 \% / \mathrm{hr}$ \\
\hline Case 2 & $-5.65 \% / \mathrm{hr}$ & $-5.45 \% / \mathrm{hr}$ & $-3.85 \% / \mathrm{hr}$ \\
\hline Case 3 & $-5.5 \% / \mathrm{hr}$ & $-3.5 \% / \mathrm{hr}$ & $-5.5 \% / \mathrm{hr}$ \\
\hline Case 4 & $-5 \% / \mathrm{hr}$ & $-9 \% / \mathrm{hr}$ & $-10 \% / \mathrm{hr}$ \\
\hline Average & $-5.71 \% / \mathrm{hr}$ & $-5.66 \% / \mathrm{hr}$ & $-5.71 \% / \mathrm{hr}$ \\
\hline
\end{tabular}

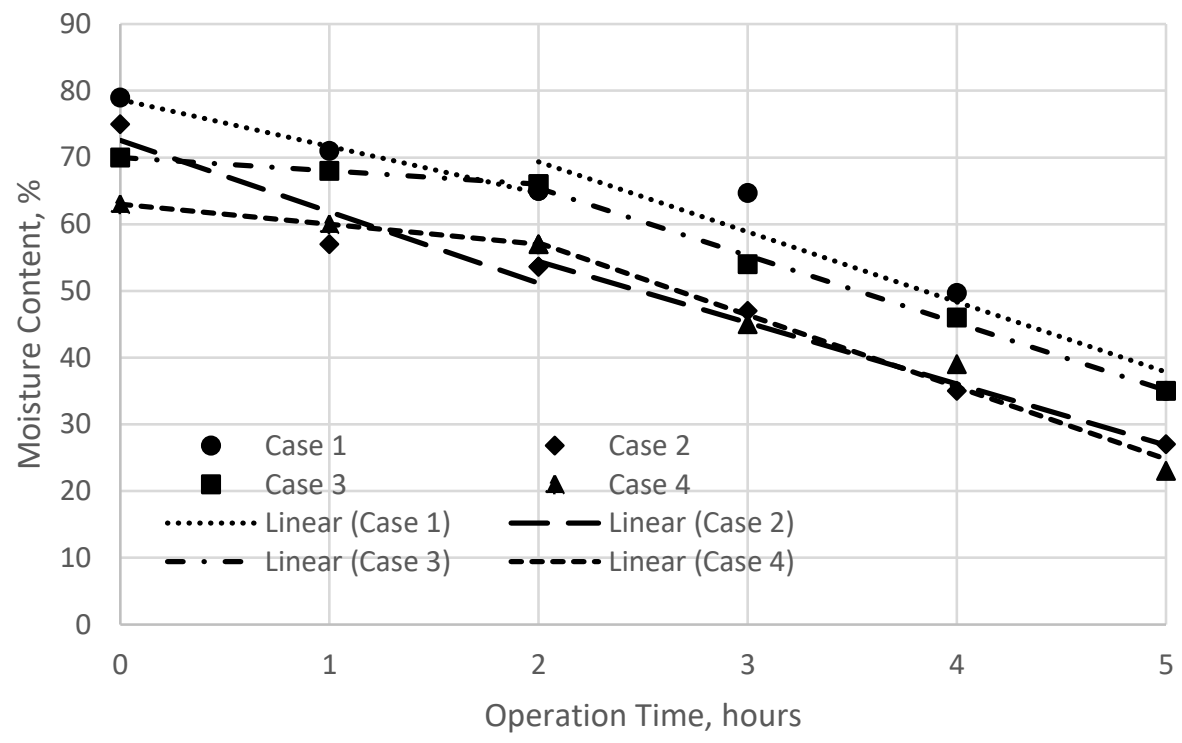

Figure 17: Medium fan speed impact of moisture loss in relation to time graph Case 1-4

Table 14: Medium speed Case 1-4 segmented regression slopes and average

\begin{tabular}{|l|l|l|}
\hline $\begin{array}{l}\text { Operating } \\
\text { Hours }\end{array}$ & $\mathbf{0 - 2}$ & $\mathbf{2 - 5}$ \\
\hline Case $\mathbf{1}$ & $-7 \% / \mathrm{hr}$ & $-10.5 \% / \mathrm{hr}$ \\
\hline Case $\mathbf{2}$ & $-10.7 \% / \mathrm{hr}$ & $-9.18 \% / \mathrm{hr}$ \\
\hline Case $\mathbf{3}$ & $-2 \% / \mathrm{hr}$ & $-10.1 \% / \mathrm{hr}$ \\
\hline Case 4 & $-3 \% / \mathrm{hr}$ & $-10.8 \% / \mathrm{hr}$ \\
\hline Average & $-5.68 \% / \mathrm{hr}$ & $-10.15 \% / \mathrm{hr}$ \\
\hline
\end{tabular}

The high-speed fan tests averaged a slope of $-6.13 \% / \mathrm{hr}$. in hours $0-2$, and slope of hours $2-5$ averaged $-11.44 \% / h r$. In the last three hours of the high-speed fan tests, more moisture was lost than in the first two. 


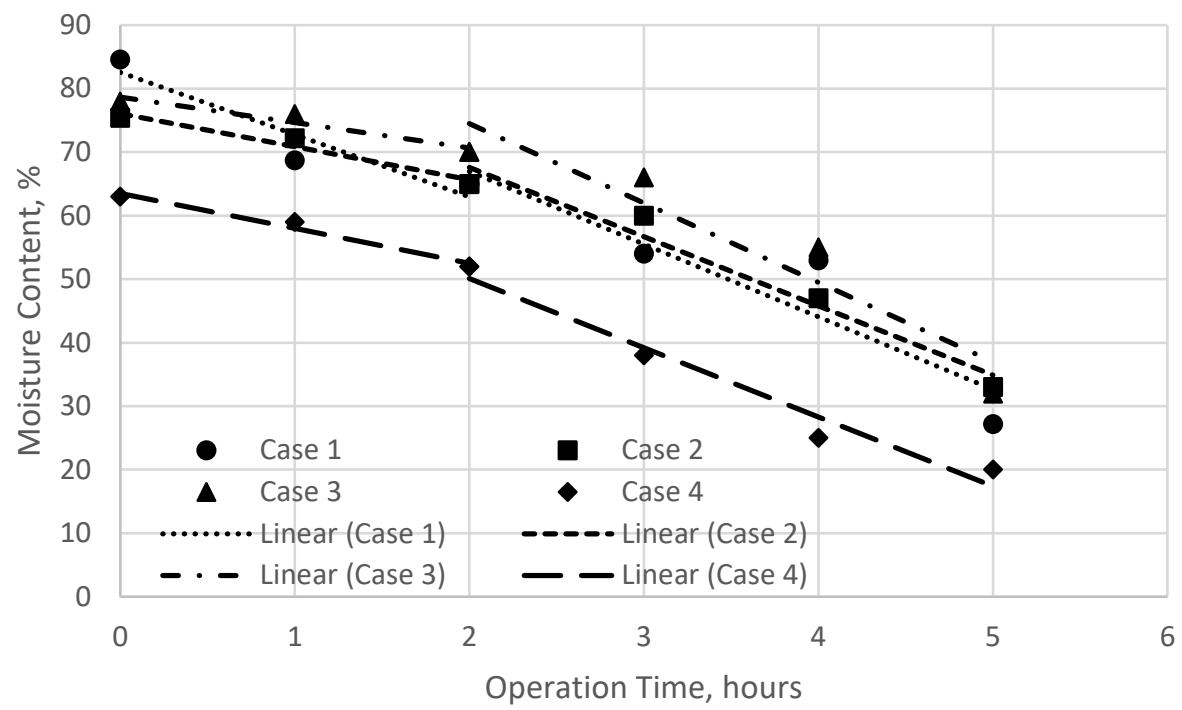

Figure 18: High fan speed impact of moisture loss in relation to time graph Case 1-4

Table 15: Low-speed Case 1-4 segmented regression slopes and average

\begin{tabular}{|l|l|l|}
\hline $\begin{array}{l}\text { Operating } \\
\text { Hours }\end{array}$ & $\mathbf{0 - 2}$ & $\mathbf{2 - 5}$ \\
\hline Case 1 & $-9.8 \% / \mathrm{hr}$ & $-11.44 \% / \mathrm{hr}$ \\
\hline Case 2 & $-5.2 \% / \mathrm{hr}$ & $-10.9 \% / \mathrm{hr}$ \\
\hline Case 3 & $-4 \% / \mathrm{hr}$ & $-12.5 \% / \mathrm{hr}$ \\
\hline Case 4 & $-5.5 \% / \mathrm{hr}$ & $-10.9 \% / \mathrm{hr}$ \\
\hline Average & $-6.13 \% / \mathrm{hr}$ & $-11.44 \% / \mathrm{hr}$ \\
\hline
\end{tabular}

In summary, the high fan speed tests shown to have a higher slope on average in comparison to the low and middle fan speed tests. Further concluding that the higher fan speed removes more moisture per hour than the tests with lower fan speeds. The low-speed tests as well showed to have a more average slope among all of the tests, removing moisture at an overall average rate of $-5.67 \% / \mathrm{hr}$. In the middle and high-speed tests, after the first two hours, the rate of moisture removal increased.

\subsubsection{Fan Speed Equations}

Through these four tests, a generalization of moisture content removed per hour equation can be developed. The rates of the air-conditioned, no air-conditioned, steam additive, and outside environment tests rates for each speed were averaged. An equation was generated based on air velocity 
of the estimated moisture content at any hour inputted. Whereas $y$ is the moisture content of the bananas, $\mathrm{m}$ is the slope or the rate of moisture content over time, $\mathrm{x}$ is the number of hours, and $\mathrm{b}$ is the moisture content of bananas at time zero.

Table 16: Moisture loss rates of the high, medium, and low speed tests of Case 1,2,3, and 4

\begin{tabular}{|l|l|l|l|}
\hline & \multicolumn{3}{|c|}{ Slope } \\
\hline Case & High Speed & Medium Speed & Low Speed \\
\hline Case 1 & -9.5964 & -8.7964 & -6.0617 \\
\hline Case 2 & -9.0571 & -8.7000 & -6.6967 \\
\hline Case 3 & -9.5714 & -8.7857 & -4.5883 \\
\hline Case 4 & -9.4571 & -7.8571 & -7.7857 \\
\hline Average & -9.4205 & -8.5348 & -6.2831 \\
\hline
\end{tabular}

The equation created from the data to calculate moisture content via fan speed is determined as followed, these equations are only applicable to this study and this data set:

Conditions to equations: $b \geq 59 \%, x \geq 0$ hours

$$
\begin{gathered}
\text { High Speed, } y=-9.4205 x+(\text { Moisture Content at time zero }) \\
\text { Medium Speed, } y=-8.5348 x+(\text { Moisture Content at time zero }) \\
\text { Low Speed, } y=-6.2831 x+(\text { Moisture Content at time zero })
\end{gathered}
$$

\section{Segmented Regression}

The same calculation of general equations was used in the segmented regression. An equation was generated for each of the different air speeds and their segmented hours. The equation is built specifically for this data set only to represent the relationship between air speed and moisture loss. In the equations, $\mathrm{x}$ is the number of hours, $\mathrm{y}$ is the moisture content of the bananas at $\mathrm{x}, \mathrm{m}$ is the slope or the rate of moisture content over time, and $b$ is the moisture content of bananas at time zero. 
Table 17: Low fan speed segmented regression equations

Conditions to equations: $b \geq 59 \%, x \geq 0$ hours, can only use the operation time specified for that equation as $\mathrm{x}$

\begin{tabular}{|l|c|c|c|}
\hline \multicolumn{3}{|c|}{ Operation Time } \\
\hline Fan Speed & $0-2$ hours & $2-4$ hours & $4-6$ hours \\
\hline Low & $y=-5.71 x+b$ & $y=-5.66 x+b$ & $y=-5.71 x+b$ \\
\hline
\end{tabular}

The medium and high fan speeds, in hours 2-5 had a higher slope than the hours of 0-2, in order to compensate for that a $10 \%$ is added to the measure moisture content at time zero because the slope intercept of the higher slope is on average $10 \%$ higher than the measured moisture content at time zero.

Table 18: Medium and high speed segmented regression equations

Conditions to equations: $b \geq 59 \%, x \geq 0$ hours, can only use the operation time specified for that equation as $\mathrm{x}$

\begin{tabular}{|l|c|l|}
\hline & \multicolumn{2}{|c|}{ Operation Time } \\
\hline Fan Speed & $0-2$ hours & $2-5$ hours \\
\hline Medium & $y=-5.675 x+b$ & $y=-10.15 x+(b+10 \%)$ \\
\hline High & $y=-6.13 x+b$ & $y=-11.44 x+(b+10 \%)$ \\
\hline
\end{tabular}

\section{Conclusions}

In conclusion, two set of tests were run to explore the different factors that affect drying time and moisture loss in a banana dehydration process. Set 1 investigated the impact that size and shape of the banana slice, humidity, and temperature had on drying time and moisture loss. Set 2 investigated the impact of air velocity, humidity, and different environmental settings on the drying time and moisture loss.

In Set 1, the shape and size of the banana did affect the drying time. The thicker the banana chips were, the longer time it took for the chips to dehydrate. The thinner the cut, the less moisture the chip contains, and the less moisture the dehydrator has to remove. Which, therefore, reduced the time needed to dehydrate the slice. The pretreatment style used in this study extended the amount of time needed to dehydrate the banana chips, especially the thicker sliced chips. The pretreatment added on 
another hour of drying time for the thicker banana chips. Temperature played a factor in moisture removal and drying time as well. Test 4 determined that the higher the temperature of the air, the higher the rate of moisture removal. Test 4 displayed that the temperature of the dehydrating environment has a direct relationship with moisture removal rate.

In Set 1 , humidity decreased through time, according to the data collected in Test $1,2,3$, and 4 . If there is air flowing in and out of the chamber removing the moisture, the air will get less humid, and the moisture held in the bananas will decrease. The decrease in the moisture of the bananas leads to less moisture being dissipated into the air, therefore decreasing the exiting air's humidity.

In Set 2, the dehydration of two bananas cut in quarter-inch slices was tested in four different environments: air conditioning, no air conditioning, steam additive, and outside ambient air. Through the analyzation of the data collected from these tests, the main concluding points were that in the more controlled environments of Cases 2 and 3, the higher the speed of the fan the faster the moisture is removed and the quicker the bananas dehydrate. Not only did the speed have an effect of the moisture removed, but so did humidity. Case 3 had steam added and had the lowest amount of moisture weight loss than Case 1 and 2, even with similar temperatures. The higher relative humidity in Case 3 affected its moisture removal rate. Specific Humidity of each Case was also related to each environmental settings. Case 1 and Case 4 had similar ranges in specific humidities due to the use of no air conditioning in both of these cases. Case 2's specific humidity was the lowest since the humidity was lowered and controlled by the air conditioning. Case 3's specific humidity was the highest among the group because of the added steam. Even though the humidity did not extend the drying time of each Case, the humidity did impact the output of the dehydration system. Specific humidity is calculated using relative humidity and temperature, so those factors play a role in the amount of moisture removed with the air. The higher the relative humidity the higher the specific humidity. 
Equations were created in Set 2 to determine the relationship between the air velocity and the moisture loss. These equations were created based on this specific data set and cannot be used to represent any other data or conditions. The high fan speed had the highest slope in the general trendline and segmented regression calculations, followed by medium fan speed, then the low fan speed. With the slope representing the rate of moisture loss, it further confirms that the higher the fan speed the more moisture is being removed.

\section{Recommendations}

Recommendation for future work is to use a more accurate method to test the moisture content of the banana chips. The Extech Psychrometer was relative in its readings and often gave different moisture content readings for the same banana slice. In this study, each slice tested for moisture content was probed until it achieved the same reading three times, which added time to the study. Finding a more effective and accurate measuring tool is highly recommended. Another recommendation is to seal the racks of the dehydrator in between readings to see if the outlet data logger reads higher values. By sealing the racks between readings more moist air could be accounted for. The final recommendation is to use bananas with a similar natural moisture content. In this research, the original moisture content of bananas varied. The readings for thicker cut bananas were especially differentiated from the original moisture content of the thinly sliced bananas, and that may be due to the bananas sliced having a different natural moisture content. By eliminating this difference, the moisture content versus dehydration time relationship could be more definitively concluded upon. Furthermore, in future work, by using bananas with only similar natural moisture content percentages, it can be determined if the mass of the banana chips plays a more significant role in the dehydrating time or the natural moisture content of the banana it is sliced from. As well in future work, testing different pretreatment methods and analyzing their impact on the dehydration process would be beneficial to understanding drying mechanics. 


\section{References}

Anonymous. 2011, "History of Food Preservation." World-Foodhistory, Blogger, , https://www.worldfoodhistory.com/2011/03/history-of-food-preservation.html

Anonymous. 2014, "History of Meat Curing Process." World-Foodhistory, Blogger, 6 May 2014, https://www.world-foodhistory.com/2014/05/history-of-meat-curing-process.html

Cengel, Y.A. and Boles, M.A. 2015, "Thermodynamics: An Engineering Approach", 8th Edition.

Cohen, Joseph S., and Tom CS Yang. 1995, "Progress in food dehydration." Trends in Food Science \& Technology 6.1: 20-25.

Fox, M., and M. Loncin. 1982, "Investigations into the microbiological stability of water-rich foods processed by a combination of methods." Lebensmittel-Wissenschaft+ Technologie $=$ Food science+ technology.

USDA. 15 June 2013, "Freezing and Food Safety." USDA Food Safety and Inspection Service, United States Department of Agriculture, www.fsis.usda.gov/wps/portal/fsis/topics/food-safety-education/getanswers/food-safety-fact-sheets/safe-food-handling/freezing-and-food-safety/CT_Index

Gould, G.W. 2012, “ New methods of food preservation. Springer Science \& Business Media.

Leistner, L. 1992, "Food preservation by combined methods." Food Research International 25.2: 151158.

Leistner, Lothar, and Leon GM Gorris. 1995, "Food preservation by hurdle technology." Trends in Food Science \& Technology 6.2: 41-46.

Linda. 2017a, "Food Preservation History: Here Explained Fully with Timeline." Dehydrator Blog, dehydratorblog.com/food-preservation-history/\#Food_Dehydration.

Linda. 2017b, "How to Pre-treat Your Food Before You Dehydrate." Dehydrator Blog, https://dehydratorblog.com/how-to-pre-treat-food-before-dehydrate/

Noback, Marlijn L., Katerina Harvati, and Fred Spoor. 2011,"Climate-related variation of the human nasal cavity." American journal of physical anthropology 145.4: 599-614.

Nummer, Brian. 2002, "Historical Origins of Food Preservation." National Center for Home Food Preservation / How Do I? Can Fruits, The University of Georgia, nchfp.uga.edu/publications/nchfp/factsheets/food_pres_hist.htm

Raymond, Joan. 2011, "The Shape of a Nose." Scientific American, Springer Nature, www.scientificamerican.com/article/the-shape-of-a-nose/.

Terenelski, Dana, and Nancy Ralph. 2003,"Pickle History Timeline." NY Food Museum, NYFM, www.nyfoodmuseum.org/_ptime.htm.

Timmermans, Louis. 2012,“Modern Fruit Drying Technologies." Center for Agribusiness and Rural Development,http://card.am/wp-content/uploads/2014/03/MODERN-FRUIT-DRYING-

TECHNOLOGIES.pdf 
Troftgruben, Judy. 1984, "Drying Food." Genetically Engineered Fruits and Vegetables, University of Illinois at Urbana-Champaign, www.aces.uiuc.edu/vista/html pubs/DRYING/dryfood.ht

Walmart. 2018, "Shark Garment Stand Steamer, GS300." Walmart.com, Walmart, www.walmart.com/ip/Shark-Garment-Stand-Steamer-GS300/15528577.

Yermudder. 2017, "Presto Dehydro ${ }^{\mathrm{TM}}$ Electric Food Dehydrator 06300." Walmart.com, www.walmart.com/ip/Presto-Dehydro-Electric-Food-Dehydrator-06300/20924338 


\section{Appendix}

\section{A: Equipment Used in Set 1\&2}

\begin{tabular}{|l|l|l|}
\hline Instruments & & Usage \\
Dehydrator with \\
PVC pipe
\end{tabular}




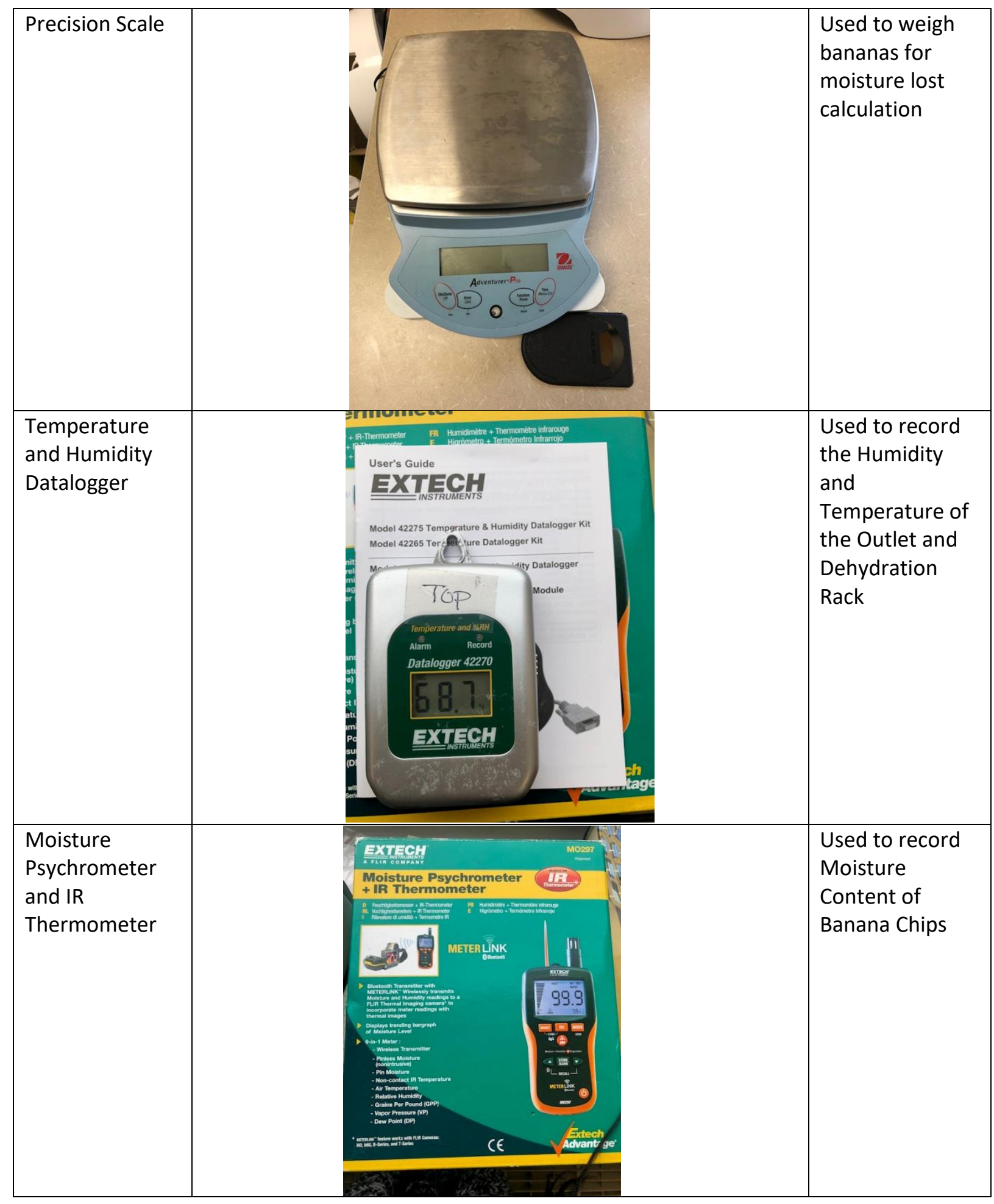




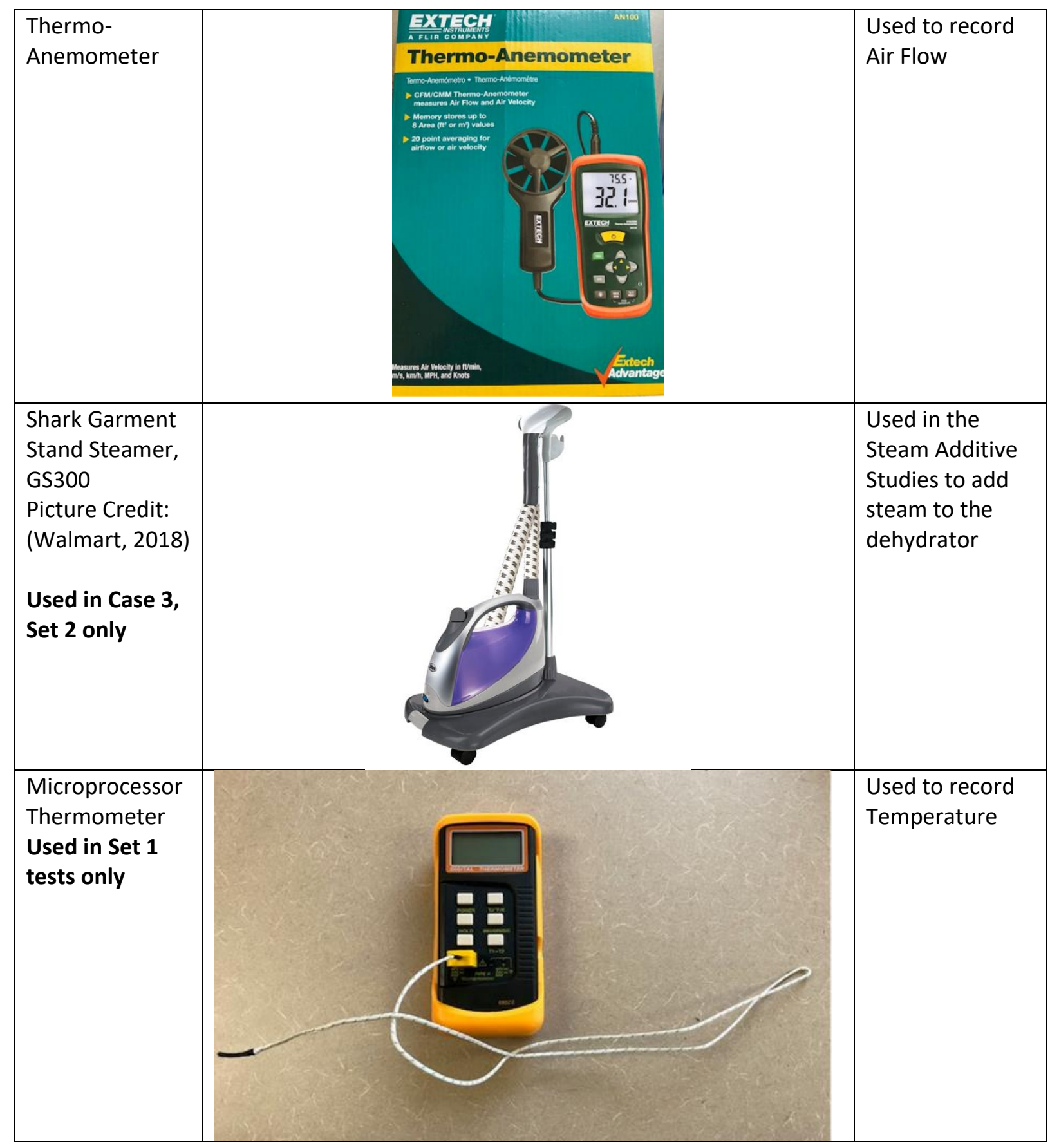




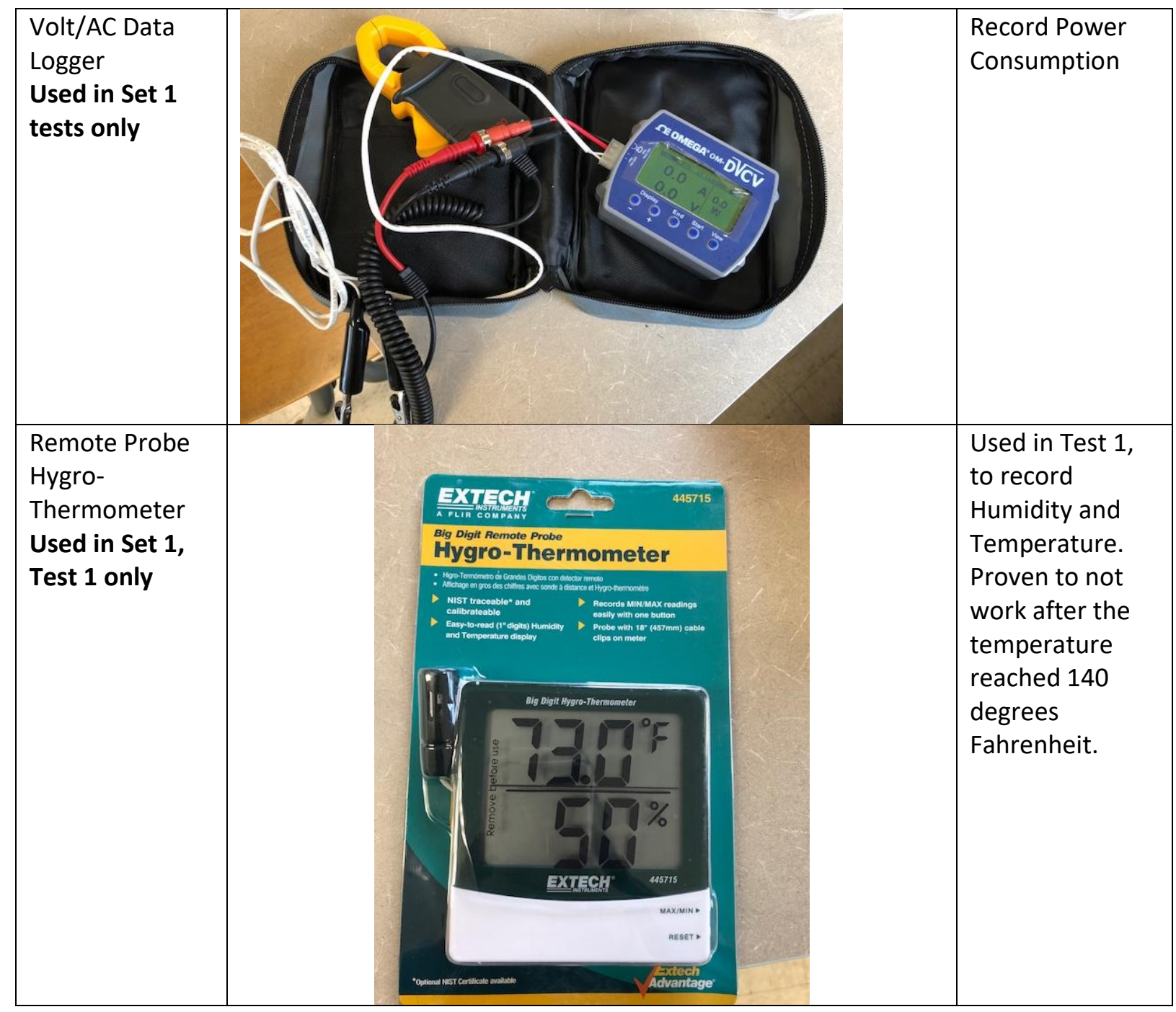




\section{B: Set 2 Equipment Setup \& Other Photos}

Photo of the speed changer, the black cord, attached to the fan of the dehydrator for Set 2 tests

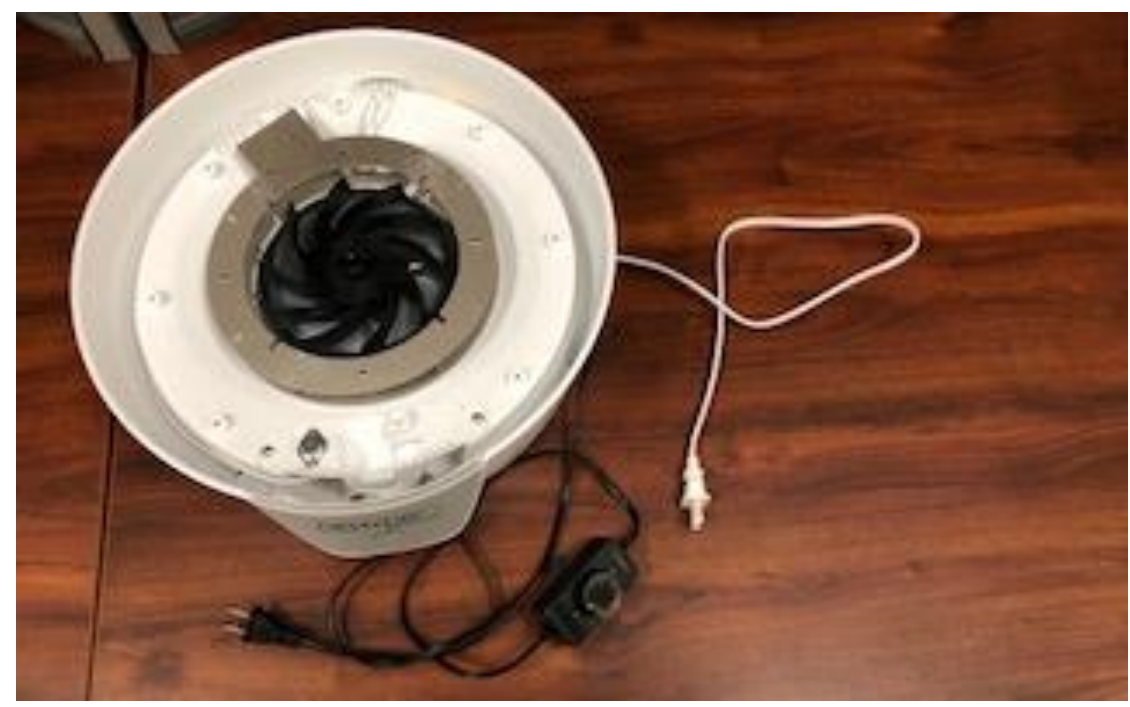

Photo of the Outside test environment setup Set 2, Case 4

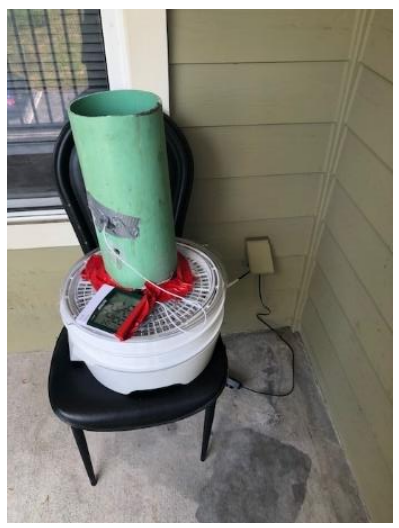


Steam Additive Test Environment Setup-Set 2, Case 3

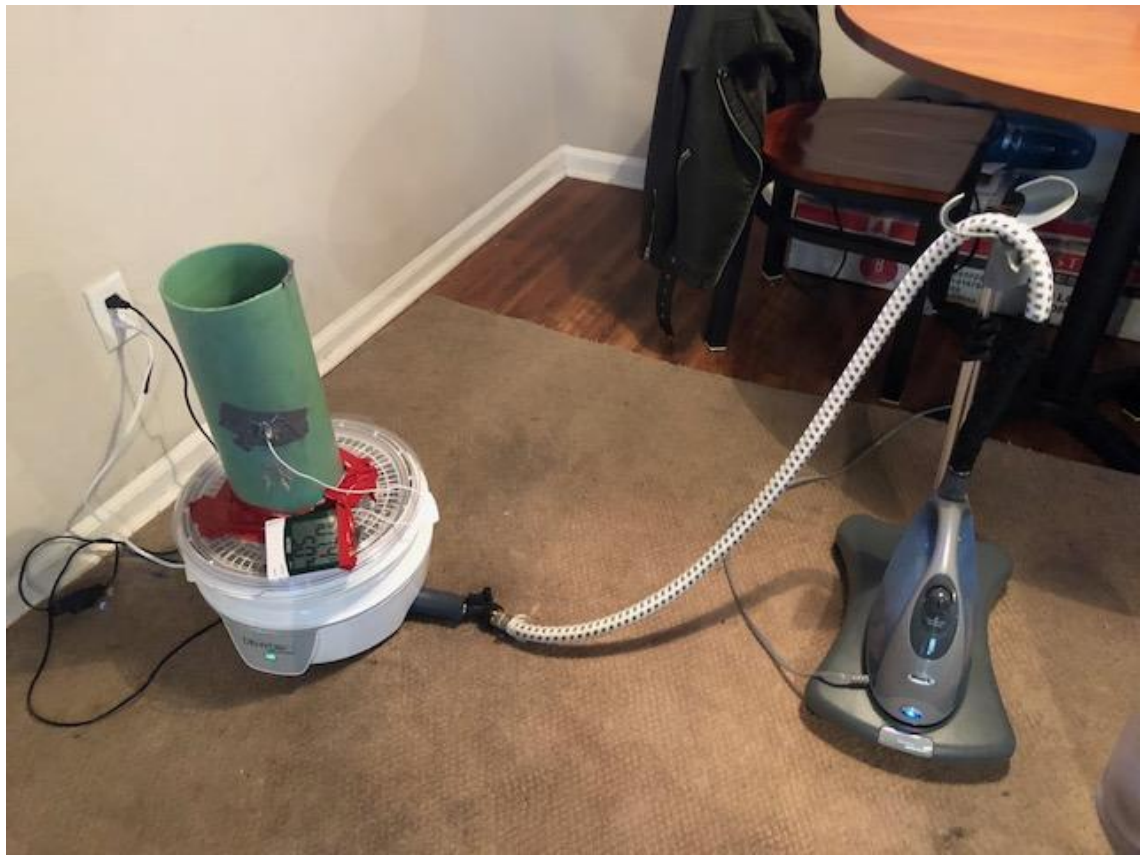

Condensation Production on top of Dehydro Steam Additive Test Low Speed-Set 2, Case 3

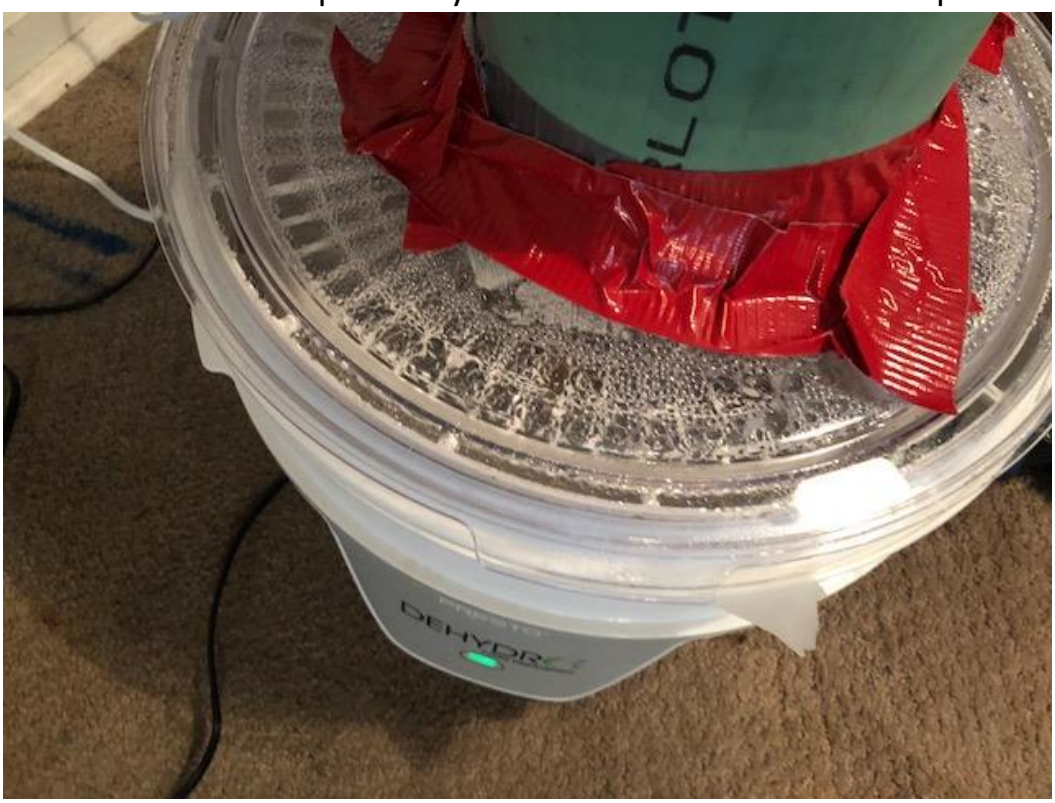




\section{C: Data Logger Results}

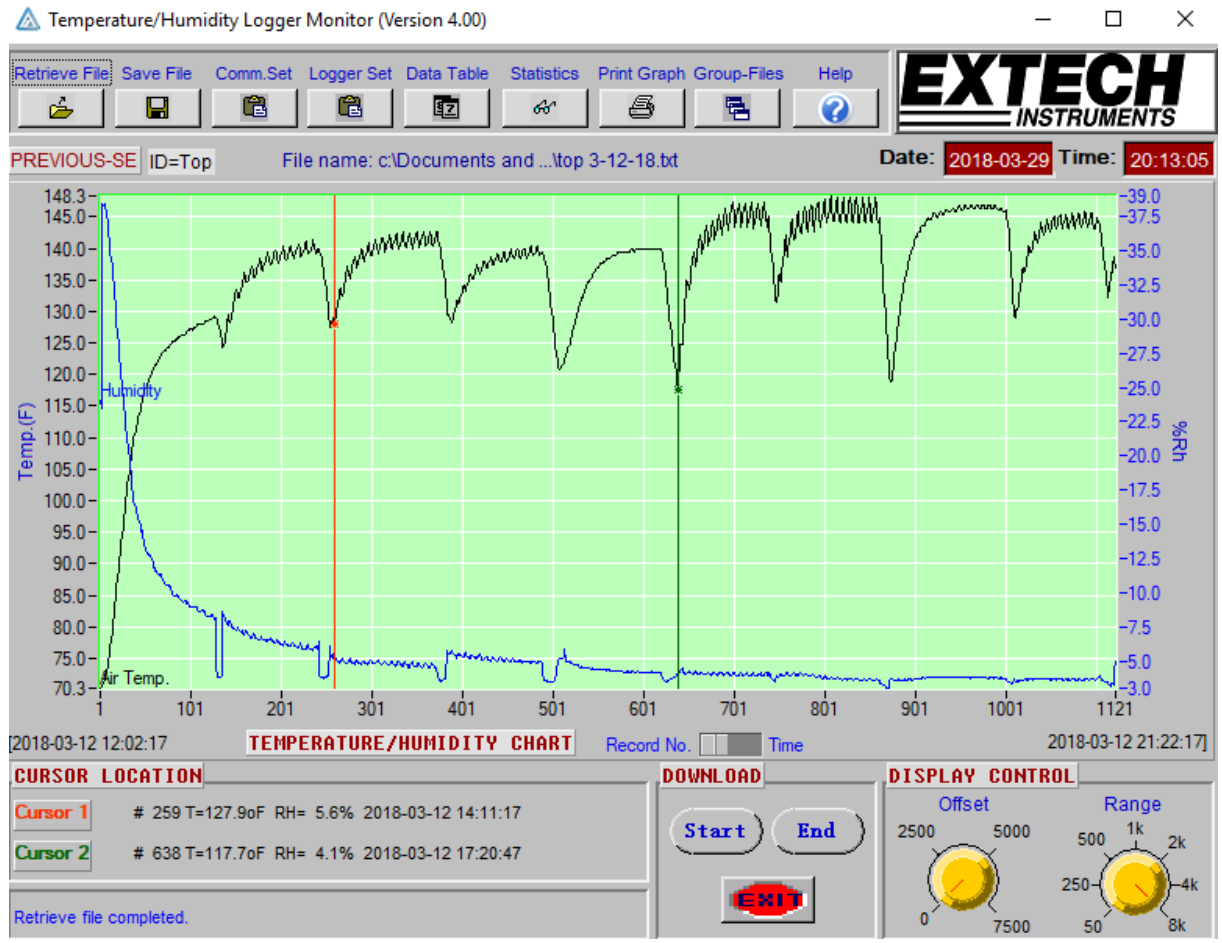

Figure 19: Test 2 humidity reading top logger 


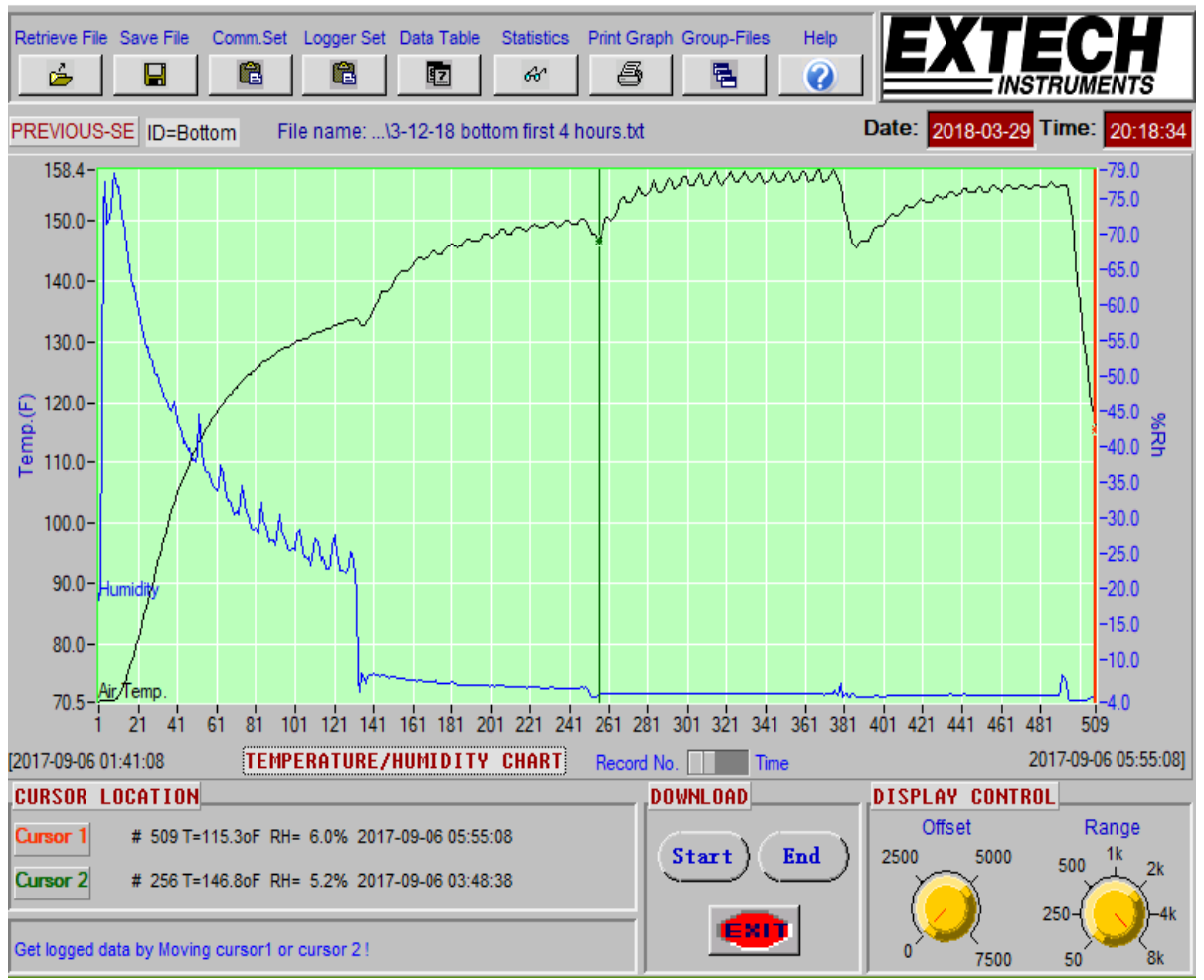

Figure 20: Test 2 humidity reading First half bottom logger

$\Delta$ Temperature/Humidity Logger Monitor (Version 4.00)

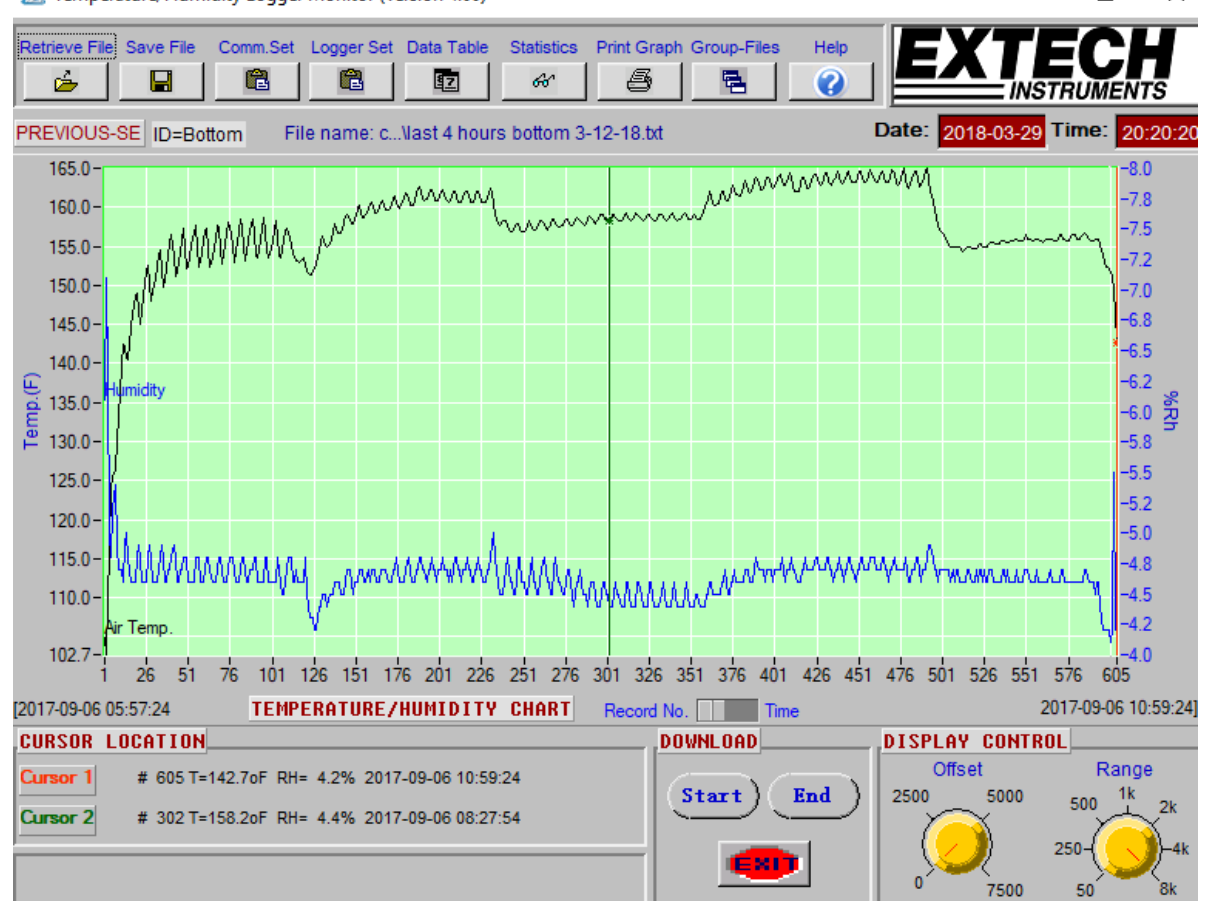

Figure 21: Test 2 humidity reading Last half bottom logger 


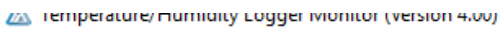

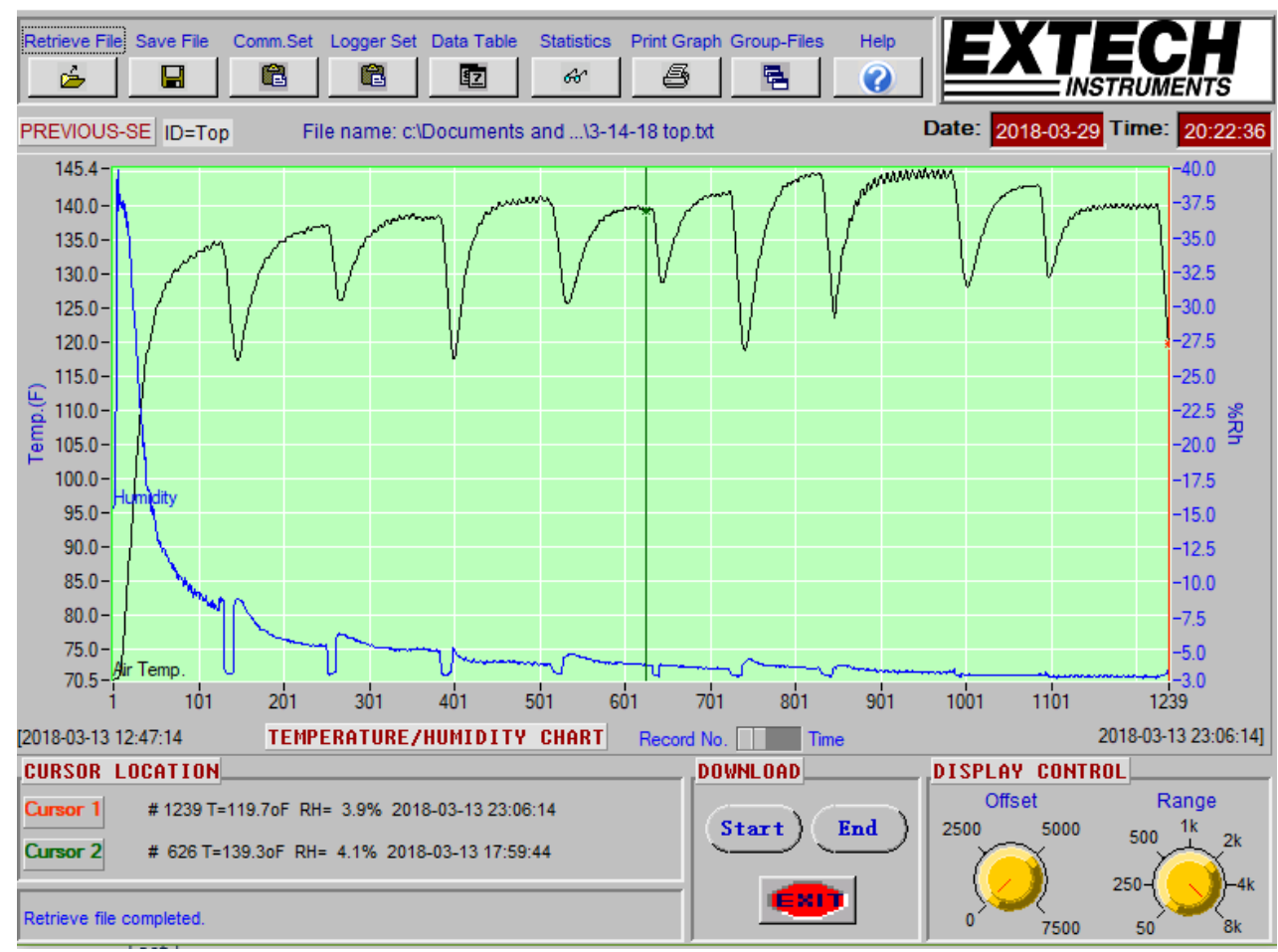

Figure 22: Test 3 humidity readings Top logger

$\Delta$ Temperature/Humidity Logger Monitor (Version 4.00)

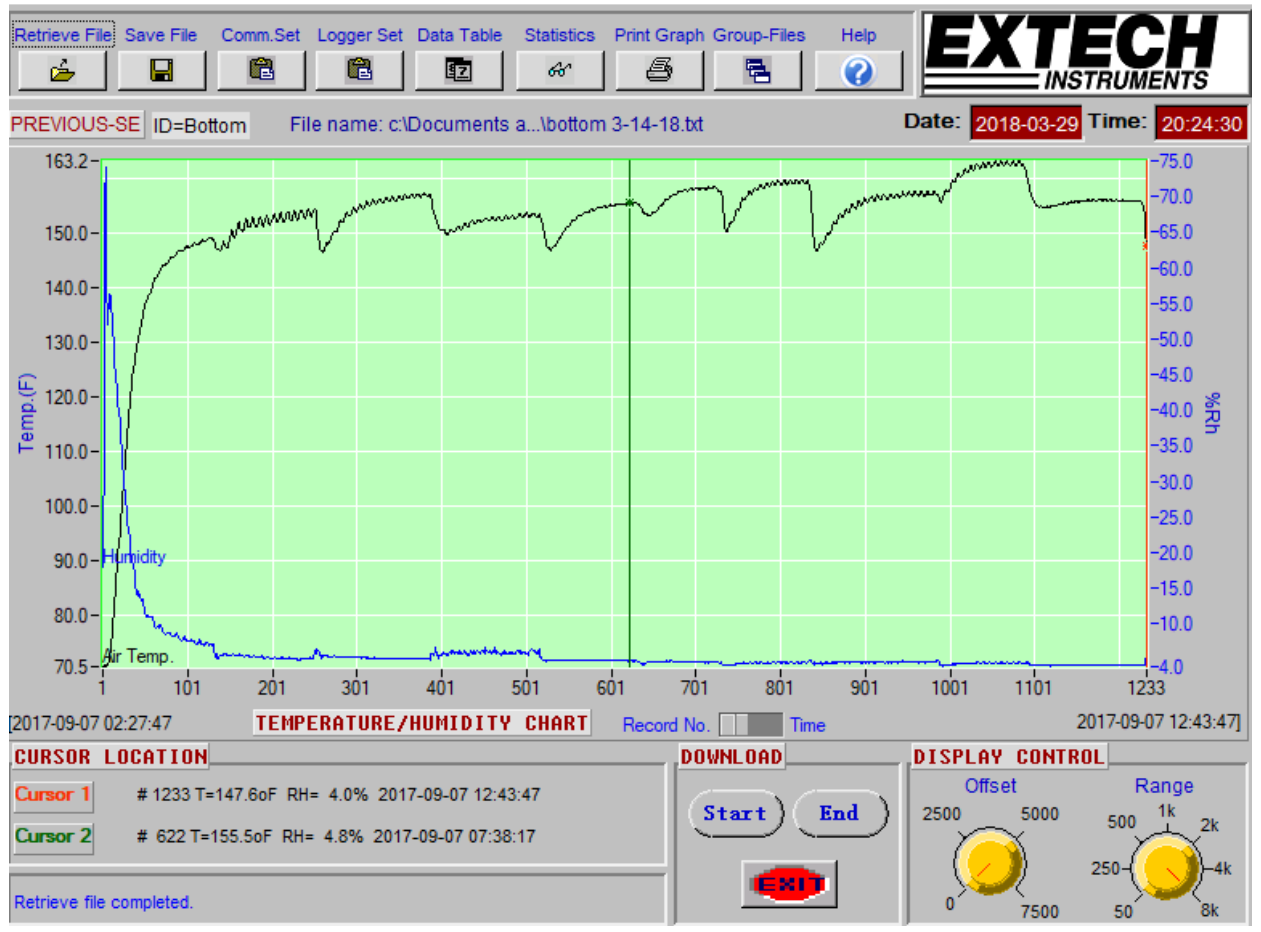

Figure 23: Test 3 humidity readings bottom logger 


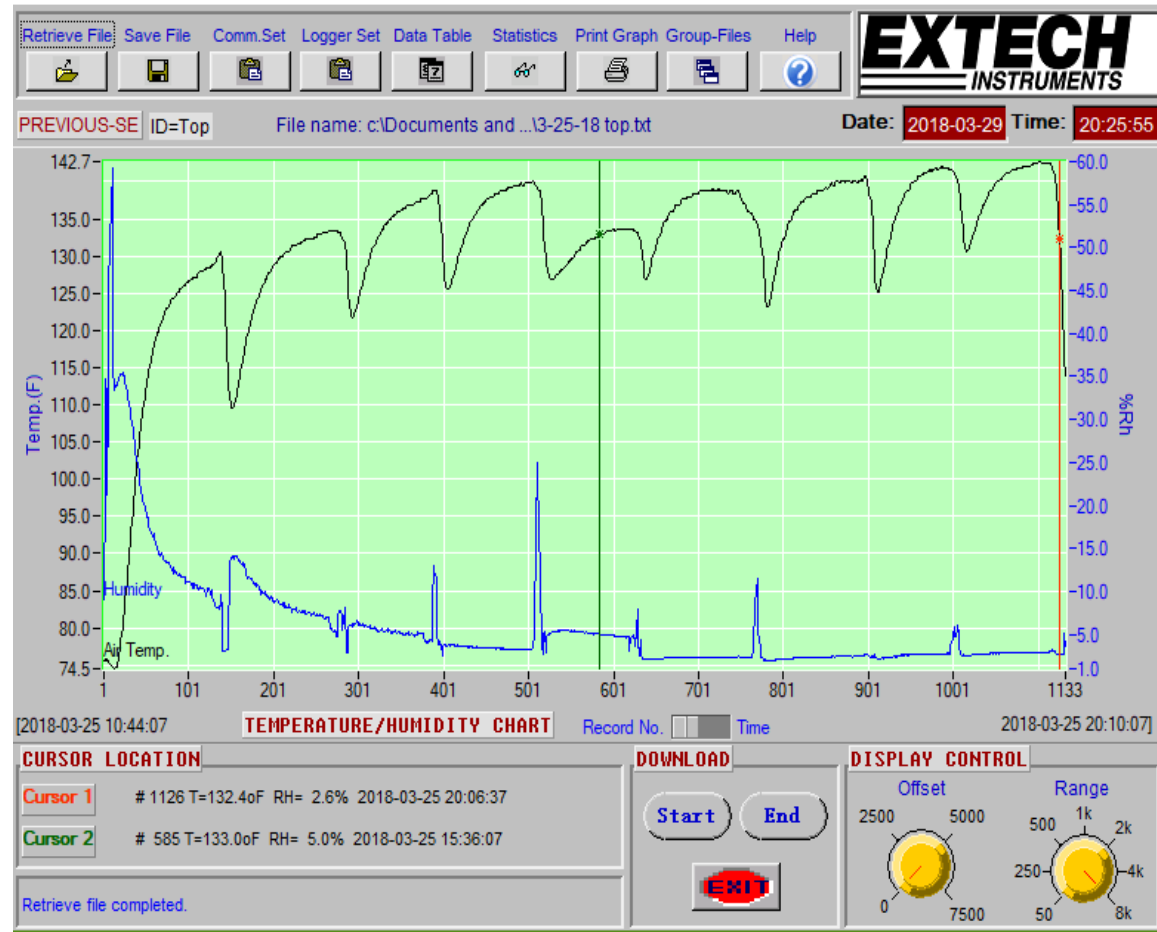

Figure 24: Test 4 humidity readings top logger

Temperature/Humidity Logger Monitor (Version 4.00)

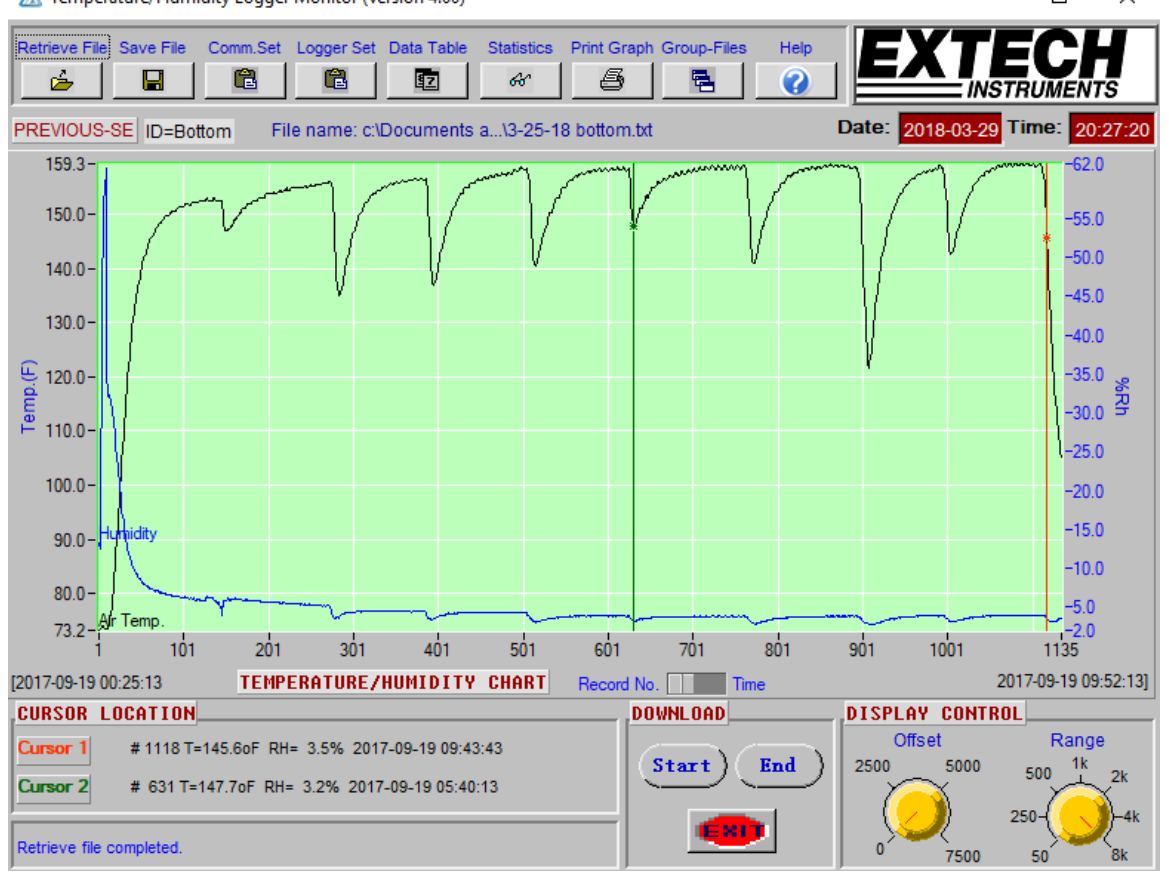

Figure 25: Test 4 humidity readings bottom logger 